\title{
THE PROFITS TO INSIDER TRADING: A PERFORMANCE-EVALUATION PERSPECTIVE
}

\author{
Leslie A. Jeng \\ Andrew Metrick \\ Richard Zeckhauser \\ Working Paper 6913 \\ http://www.nber.org/papers/w6913
NATIONAL BUREAU OF ECONOMIC RESEARCH 1050 Massachusetts Avenue
Cambridge, MA 02138
January 1999

We thank Mirium Avins, Keith Higgins, Immoo Lee, Mike Pascutti, Jay Patel, Eric Sirri, and Andrei Shleifer for helpful comments. We acknowledge financial support from Harvard Business School (Jeng) and the Hernstein Fund (Metrick and Zeckhauser). The views expressed here are those of the author and do not reflect those of the National Bureau of Economic Research.

(1) 1999 by Leslie A. Jeng, Andrew Metrick, and Richard Zeckhauser. All rights reserved. Short sections of text, not to exceed two paragraphs, may be quoted without explicit permission provided that full credit, including ${ }^{\circledR}$ notice, is given to the source. 
The Profits to Insider Trading:

A Performance-Evaluation Perspective

Leslie A. Jeng, Andrew Metrick, and Richard Zeckhauser

NBER Working Paper No. 6913

January 1999

JEL No. G14, G28

\section{ABSTRACT}

This paper estimates the profits to insiders when they trade their company's stock. We construct a rolling "purchase portfolio" that holds all shares purchased by insiders over the previous year and an analogous "sale portfolio" that holds all shares sold by insiders over the previous year. We then analyze the returns to these value-weighted portfolios using performance-evaluation methods. This approach allows us to study the returns to insider transactions beginning on the day after their execution, and is free of the statistical difficulties that plague event studies on longhorizon returns. Using a comprehensive sample of reported insider transactions from 1975 - 1996 , we find that the purchase portfolio earns abnormal returns of about 40 basis points per month, with about one-sixth of these abnormal returns accruing within the first five days after the initial transaction, and one-third within the first month. The sale portfolio does not earn abnormal returns. Our portfolio-based approach also allows for straightforward decompositions of the purchase and sale portfolios by various characteristics. We find that the abnormal returns to insider trades in small firms are not significantly different from those in large firms, and that top executives do not earn higher abnormal returns than do other insiders.

Leslie A. Jeng

Dept. of Finance and Economics Boston University School of Mgmt., $515 \mathrm{G}$ 515 Commonwealth Ave.

Boston, MA 02215

ljeng@bu.edu

Richard Zeckhauser

JFK School of Government

Harvard University, L312

79 JFK Street

Cambridge, MA 02138

and NBER

richardz@ksg1.harvard.edu
Andrew Metrick Department of Economics

Harvard University Littauer Center, North Yard

Cambridge, MA 02138

and NBER

ametrick@harvard.edu 


\section{Introduction}

When corporate insiders trade their company's stock, how much do they profit? What kinds of stocks offer the greatest profits? Are high-volume trades more profitable than lowvolume trades? What is the expected cost to "outsiders" due to possible transactions with insiders?

In this paper, we answer these questions using a comprehensive sample of reported insider transactions from 1975 to 1996 . The principal innovation in our approach is the construction of value-weighted portfolios comprised of all insider trades. This portfolio-based approach applies performance-evaluation methods to analyze the returns of insiders' trades from the day they are executed. These methods provide answers to new questions and offers fresh insights into old ones.

By law, corporate insiders must file monthly SEC reports about their trades in their company's stock, and these reports are quickly made public. ${ }^{1}$ This data on insider trading has inspired a large academic literature that studies the cross-sectional variation of stock returns as a function of insider-trading activity. Representative articles include Lorie and Niederhoffer (1968), Jaffe (1974), Seyhun (1986) and (1998), Rozeff and Zaman (1988), Lin and Howe (1990), and Lakonishok and Lee (1998). ${ }^{2}$ This literature focuses on the abnormal returns to firms depending on the "intensity" of insiders' purchases and sales over well-defined periods. For example, a stock may be labeled an "insider buy" for a month if at least three insiders bought the stock and no insiders sold it. Alternatively, the definition may rely on the net number of shares purchased and sold by insiders during the month. We refer to such rules as "intensive-

\footnotetext{
${ }^{1}$ Section 2 discusses the definition of a corporate insider, and the regulation and reporting requirements of their trades.

2 A closely related literature that studies insiders' ability to forecast the time-series of aggregate stock returns, a topic we do not discuss in this paper. See Seyhun (1988), (1992), and (1998), and Lakonishok and Lee (1998).
} 
trading" criteria. These studies use a variety of intensive-trading criteria for many different samples, and are nearly unanimous in the conclusion that stocks that are intensely bought tend to outperform relevant benchmarks over a subsequent period, and that those that are intensely sold tend to underperform. They provide mixed evidence on whether other investors can profit, after transactions costs, by using the public information contained in the insider trading reports. Seyhun (1998) summarizes this evidence and concludes that several different trading rules lead to profits.

The research cited above can be interpreted as tests of both the "strong" and "semistrong" versions of the efficient-markets hypothesis. If, for example, intensively purchased stocks earn abnormal returns, then this would be evidence against the strong form. If outsiders can use the public filings of insiders to construct successful trading strategies, then this would be evidence against the semi-strong form (Fama, 1971). While intensive-trading criteria illuminate the efficient-markets hypothesis, the approach encounters two challenges. First, the requirement that intensity be defined over some interval means that stocks are only classified after these intervals end. Therefore, the returns on the days immediately following most trades are not included in the analysis. Second, the use of individual stocks as the main unit of analysis makes it impossible to determine a value-weighted return to all trades; the stocks with intensive buying or selling activity may comprise a small or a large part of overall trading. Attempts to overcome these challenges by using event-study methods on daily returns for all trades (Pascutti, 1996) encounter statistical difficulties due to both cross-sectional correlation and biases in computing long-run abnormal returns. ${ }^{3}$

\footnotetext{
${ }^{3}$ See Barber and Lyon (1997), Barber, Lyon, and Tsai (1998), and Kothari and Warner (1997).
} 
In this paper, we surmount these difficulties by adopting a value-weighted portfoliobased approach. We imagine that all insider purchases are placed into a portfolio on the day that they are made and held for exactly one year. This "purchase portfolio" is like a shadow mutual fund "managed" by the combination of all insiders. Since the holdings in this portfolio are weighted in proportion to the values of the underlying insider trades, the returns on the portfolio would correspond to the value-weighted returns earned by all insider purchases over one year. Similarly, we can imagine a "sale portfolio" comprised of all shares sold by insiders, with these shares held in the portfolio for exactly one year.

We use these constructed purchase and sale portfolios to assess the timeliness of insider transactions. For some purposes, we might prefer instead to calculate the actual profits that insiders make from their purchases and sales. Unfortunately, this is not possible: we have no way to determine the actual holding period for insider purchases. For sales, there may be no equivalent to a holding period, since a restorative purchase may never be made. Bearing such difficulties in mind, we employ a one-year holding period for the stocks that insiders buy, and calculate hypothetical insider profits from purchases on this basis. Thus, we are arbitrarily defining "profits" to be "abnormal returns earned in the one-year period from date of acquisition". We say that the purchase portfolio earns a profit if its returns exceed a relevant benchmark portfolio; in this case insiders are profiting by being in their own stock instead of the benchmark for the one-year period from date of acquisition. In parallel fashion, we say the sale portfolio "profits" if its returns fall below those of its relevant benchmark portfolio; with the sale portfolio, insiders are profiting by investing in the relevant benchmark instead of their own stock for the one-year period following date of sale. 
These constructed purchase and sale portfolios allow for a novel perspective on insider profits, made possible by two useful methodological devices. First, daily updating of the portfolios allows us to include all stocks' immediate post-trade performances in the analysis. Second, the returns to the purchase and sale portfolios can be analyzed using performanceevaluation methods and are free of the statistical difficulties that plague long-horizon event studies. Another advantage of the value-weighted portfolio approach is that it allows simple decompositions of the portfolios by time horizon, firm characteristics, and trading volume. By constructing subportfolios, we can obtain point estimates and standard errors for the abnormal returns to value-weighted insider trades conditional on each of these elements.

Beyond the scientific benefits, our estimation of insider profits is also motivated by policy concerns: What are the welfare implications of the profits to insider trading? There is a range of opinion. ${ }^{4}$ Some laissez-faire observers believe that insider trading should be legal, and that profits from it should be part of corporate compensation. At the opposite extreme, financial Puritans would object to the insiders' profits as unjust enrichment, even if there were no consequences for market (or corporate) performance. ${ }^{5}$

Lying in between is the position of American regulators, whose principal concern must be whether the playing field is level: Profitable insider trading is bad as a symptom of markets that are unfair to the outside investor, who is trading at an informational disadvantage. This is unfair in itself, and furthermore undermines outsiders' confidence in such markets, diminishes their willingness to trade, and thereby reduces liquidity and efficiency within financial markets. The regulators' market-performance concern depends on perceptions of market fairness, not

4 See Bainbridge (1998) for a survey of this debate.

5 Their disapproval would not vanish, even if it could be demonstrated that insider trading brought significant net benefits, say because it brought stock prices more firmly into alignment with appropriate values. Their historical ancestors objected to bear-baiting, not because of the suffering of the bear, but because of the pleasure of the people. 
necessarily reality. It is virtually impossible for outsiders to assess their disadvantage in such markets, absent the detailed analysis to which we now turn.

Two other studies employ variants of the portfolio approach used in our paper. Finnerty (1976) uses the CAPM to evaluate the equally weighted returns to all insider trades in NYSE stocks from 1969 to 1972 . Though equal weighting is reasonable for his study, which is motivated as a test of the strong form of market efficiency, it leaves open the same questions as do studies based on intensive-trading criteria. Eckbo and Smith (1998) use performanceevaluation methods on monthly data for the complete sample of value-weighted insider holdings in Norway from 1985 to 1992 . In contrast to the results on U.S. data, they find that insiders do not earn abnormal returns. The difference between their results and those for the U.S. may stem from differences in a variety of institutional and methodological sources. This is further motivation for a study of insider trading in the U.S. using our portfolio approach.

Overall, our evidence shows that insiders profit from their purchases but not from their sales. In raw returns, the purchase portfolio outperforms the market by about 7.4 percent per year. Using several performance-evaluation methods, we find that about one-third of this outperformance can be explained by insiders' propensity to buy small stocks, "value" stocks, and those with higher market betas. Across the different methods, the remaining abnormal performance ranges between 37 and 47 basis points per month. These point estimates are similar to those found in studies that use intensive-trading criteria. We find that about one-sixth of these abnormal returns accrue within the first five days after the trade, one-third within the first month, and three-quarters within the first six months.

Despite the economically significant profits to insider purchases, we find that counterparties (“outsiders") have little to fear from these reported transactions. Insider trades 
make up but a tiny portion of the market. On a value-weighted basis, insider purchases make up only about 0.03 percent of total market volume, so the expected "cost" to outsiders due to the purchases of insiders is about 0.15 basis points per year. ${ }^{6}$

In raw returns, the sale portfolio has about the same performance as the value-weighted market. Consistent with previous studies, we find that insiders tend to sell "growth" stocks that have performed well in the recent past. When we use performance-evaluation methods and control for this tendency, all methods yield abnormal returns that are both economically and statistically insignificant. This result differs from the literature on insider trading, where most studies find negative abnormal returns for stocks that are intensely sold by insiders. Our use of value weighting, as opposed to some intensity measure, is the most likely cause of this difference. We also document a significant positive abnormal return for the first five days after sale transactions. We provide evidence to show that this anomaly is caused by marketmicrostructure effects following high-volume sales.

Following our analysis of the purchase and sale portfolios, we look at the portfolios decomposed along several dimensions: volume of the trade, size of the firm, insider's position in the firm, and whether the trade is executed directly for an insider or indirectly for another party. These categories have previously been studied using intensive-trading criteria or event-study methods to study market efficiency and to search for profitable trading rules based on the public filings of insiders. ${ }^{7}$ Our goals are different. We ask, "how much do insiders profit?" from each type of trade. We find that several of the results from intensive-trading studies do not extend to our framework. For example, we find that insiders in small firms do not earn significantly

\footnotetext{
6 Details of this calculation are provided in Section 4.

7 See Seyhun (1986) and (1998), Pascutti (1996), Lakonishok and Lee (1998).
} 
higher profits than do insiders in large firms, and top executives do not earn significantly higher profits than do other insiders.

The paper is organized as follows. Section 2 discusses the data and provides summary statistics. Section 3 describes the three performance-evaluation methods we employ. Section 4 gives the performance-evaluation results for the main insider-purchase and insider-sale portfolios. Section 5 analyzes decompositions of the purchase and sale portfolios by trade volume, firm size, and the insider's relationship to the firm. The conclusion summarizes our results and puts them in context.

\section{Data and Summary Statistics}

The Securities and Exchange Act of 1934 (SEA) prohibits agents from trading securities while in possession of material inside information. "Material insider information" can be loosely defined as private information that a reasonable investor would consider important in the decision to buy or sell a corporation's security. ${ }^{8}$ The enforcement of the SEA was substantially strengthened by the Insider Trading Sanctions Act of 1984 and the Insider Trading Fraud Enforcement Act of 1988. In response, many companies instituted their own restrictions on insider trading to avoid any appearance of illegality. ${ }^{9}$ Do current restrictions and enforcement measures prevent corporate insiders from trading profitably? That is the motivating question of this paper.

To facilitate enforcement of the regulations, Section 16(a) of the SEA requires that openmarket trades by corporate insiders be reported to the Securities and Exchange Commission (SEC) within ten days after the end of month in which they took place. For the purposes of this

\footnotetext{
8 For a detailed discussion of the SEA, see Bainbridge (1998).
}

9 Jeng (1998). 
reporting requirement, "corporate insiders" include officers with decision-making authority over the operations of the company, all members of the board of directors, and beneficial owners of more than ten percent of the company's stock. These reports, filed on the SEC's "Form 4", are the source of data for almost all of the empirical studies of insider trading. ${ }^{10}$ Our data is drawn from these Form 4 filings for the period from January 1, 1975 to December 31, 1996. These filings contain information about each transaction and about the insider's relationship to the firm. (See Appendix A for more information about Form 4.)

Our analysis focuses on open-market purchases and sales by officers and directors. We exclude options exercises, private transactions, and all transactions by beneficial owners. The resulting database contains 563,863 transactions from 1975 to 1996, of which 214,897 are purchases and 348,966 are sales. ${ }^{11}$ Sales outnumber purchases particularly in later years when option and stock awards began to become a significant part of officers' and directors' compensation; such awards do not show up as purchases, but they do show up as sales when the positions are liquidated. The typical sale is substantially larger than the typical purchase, with average dollar values of $\$ 136,260$ per sale as compared with $\$ 35,580$ per purchase.

On a value-weighted basis, what percentage of all trades are made by insiders? This percentage is straightforward to calculate as the dollar volume of insider purchases and sales divided by the dollar volume of all trades. We calculate these percentages separately each month for both purchases and sales, and we plot the time-series of these percentages in Figure 1. Over the whole sample period, the average monthly ratio of value-weighted insider sales to all trades is 0.22 percent. Thus, an outsider making a purchase would expect 0.22 cents per dollar to be

10 Two exceptions are Meulbroek (1992), who studies illegal (and unreported) insider trading, and Gompers and Lerner (1998), who study venture capital distributions.

11 We performed several steps to purge the data of coding errors. See Appendix A. 
with insiders. The average monthly ratio of insider purchases to all trades is 0.03 percent. Thus, outsiders making sales would expect only 0.03 cents per dollar from insiders.

Many studies of insider trading show that insiders sell stocks after they rise and buy them after they fall. ${ }^{12}$ We also see this in our sample, as Figure 2 illustrates. We calculated an abnormal return for every trade on every day, where abnormal returns are defined as the stock's return minus the return on the value-weighted market (NYSE/AMEX/Nasdaq). Cumulative abnormal returns (CARs) are measured relative to the trading day by adding the daily abnormal returns for all intervening days. These CARs are then averaged across all firms and graphed in the figure. Thus, this analysis equally weights all trades beginning on the day of their execution.

Figure 2 shows that, on average, an insider sale is preceded by a positive CAR of about 12 percent over the preceding 100 days, but has no noticeable CAR after the sale. Purchases are preceded by a negative CAR of about two percent over the 100 days prior to the trade date, and are followed by a positive CAR of about six percent over the subsequent 100 days.

The average CARs graphed in Figure 2 provide only a crude measure of the abnormal returns of insider trades. Aside from the obvious difficulties of using the value-weighted market as the expected-return proxy for all stocks, there are also statistical problems due to biases in the computation of CARs and the cross-sectional dependence of the abnormal returns among transactions of the same firm and across firms. ${ }^{13}$ We sidestep these problems by constructing "purchase" and "sale" portfolios and analyzing their returns with performance-evaluation methods. To construct the purchase portfolio, we "buy" all insider purchases at the closing prices on the day of the actual trades. ${ }^{14}$ We then hold these shares in the portfolio for one year.

12 Seyhun (1986) and (1998), Lakonishok and Lee (1998), Rozeff and Zaman (1998).

${ }_{13}^{13}$ See Barber and Lyon (1997), Kothari and Warner (1997), and Barber, Lyon, and Tsai (1998).

${ }^{14}$ We use closing prices on the day of the trade rather than the actual transaction prices of the insider transaction because of concerns about errors in the reporting of transaction prices. Please see Appendix A for a complete discussion of this issue. 
Thus, the purchase portfolio includes all shares purchased by insiders over the previous year. Similarly, the sale portfolio contains all shares sold by insiders over the previous year.

Figure 3 plots the total market value of the purchase and sale portfolios as a fraction of the overall market. The series begins on January 1, 1976, so that both the portfolios have a full year of history at all times. ${ }^{15}$ As would be expected, the sale portfolio is always larger than the purchase portfolio. With all sales held for one year after the insider transaction, the sale portfolio averages about 0.11 percent of the market. It is largest in recent years and reaches a peak of 0.23 percent of the market in 1994. The size of the purchase portfolio averages about 0.02 percent of the market and does not demonstrate any obvious pattern over time.

The purchase and sale portfolios are likely to differ along many dimensions. First, we would expect to observe more insider sales than purchases, if only for diversification and liquidity motives. High-ranking corporate officers typically have substantial human capital invested in their firms and often have large holdings of corporate stock and options relative to their wealth. ${ }^{16}$ In addition, much executive compensation comes in the form of stock and options, and these additions to insiders' personal portfolios will not show up in our database. In fact, a value-weighted plot of option exercises (not shown here) shows a striking similarity to the plot of sales given in Figure 1; such similarity would be expected if many sales are executed in conjunction with option exercises. Overall, we would expect that insider purchases are more likely than sales to be information-driven.

Second, the purchase and sale portfolios differ from each other and from the overall market in their stock composition; insiders tend to trade in stocks that are smaller in market

\footnotetext{
15 After January 1, 1976, the purchase and sale portfolios will have a full year of transactions in them. During 1975, the portfolios will necessarily be truncated as of January 1, 1975. Therefore, for consistency, we begin all the analyses of the purchase and sale portfolios on January 1, 1976, and refer to our sample as beginning on that date. 16 Hall and Liebman (1998).
} 
capitalization than the "average" stock, with this pattern more pronounced for purchases. ${ }^{17}$ As an illustration, we compute the fraction of the purchase and sale portfolios made up by the largest and smallest stocks and we compare these fractions with analogous fractions for the whole market. These fractions are computed for July 1 of each year and then averaged across all years from 1976 to 1996. We define the "largest" stocks as those with market equities above the cutoff for the largest third of the stocks on the NYSE. Analogously, the "smallest" stocks are those with market capitalizations below the cutoff for the smallest third. Using these cutoffs, we classify all stocks traded on NYSE, AMEX, and Nasdaq. Naturally, the largest stocks comprise a far larger component of the value of the overall market (83.1 percent) than the smallest stocks (5.5 percent). In contrast, the sale portfolio derives only 38.0 percent of its value from the largest stocks and 29.1 percent from the smallest stocks. The purchase portfolio has an even more extreme tilt toward small stocks, with only 22.0 percent of its value from the largest stocks and 41.2 percent from the smallest stocks.

Rozeff and Zaman (1998) and Lakonishok and Lee (1998) show that insiders tend to buy "value" stocks and sell "growth" stocks, as defined by several different value and growth measures. This pattern also emerges in our purchase and sale portfolios, and can be illustrated with a portfolio decomposition similar to the one we did for size. On July 1 of each year, we calculate a book-to-market (BM) ratio for all stocks using their book value for the most recent fiscal year (from COMPUSTAT) divided by market value as of the previous December 31 . We then rank all NYSE stocks by their BM ratios and find the cutoffs for the highest third ("value") and the lowest third ("growth"), and we use these cutoffs to classify all stocks. Next, we calculate the fractions of the purchase portfolio, sale portfolio, and overall market that fall into the value and growth categories. These fractions are computed once per year and then averaged

17 Seyhun (1986) and Rozeff and Zaman (1988). 
across all years from 1976 to 1996 . Using these definitions, the overall market consists of 50.2 percent growth stocks and 20.3 percent value stocks (and 29.5 percent in between). Relative to the market, the sale portfolio demonstrates a slight tilt toward growth stocks, with 52.8 percent growth and 17.1 percent value. The purchase portfolio exhibits a strong value tilt, with an average of 34.1 percent growth and 34.8 percent value.

What are the returns to the purchase and sale portfolios? Figure 4 plots the value over time for a hypothetical investment of $\$ 1$ on January 1, 1976. Consistent with the results of Figure 2, the purchase portfolio outperforms the market, while the sale portfolio earns returns very close to the market. The annualized returns are 23.0 percent for the purchase portfolio, 16.4 percent for the sale portfolio, and 15.6 percent for the market. ${ }^{18}$ Of course, simple comparisons of portfolio returns to the market tell only part of the story. To learn more, we need to use performance-evaluation methods and calculate abnormal returns. We turn to this task in the next section.

\section{Performance Evaluation of Insider Trades}

In the section, we describe the performance-evaluation methods that we use to analyze insider's returns. Since there is no consensus on the "right" model of expected returns, we employ three methods that have proved useful in similar studies. Our first method of performance evaluation is the standard CAPM of Sharpe (1964) and Lintner (1965).

18 This calculation ignores transactions costs, a policy that we follow throughout the paper and one that is consistent with our purposes. One could easily approximate the annual transactions costs for these portfolios by multiplying portfolio turnover (100 percent, by construction) by an estimate of round trip transactions costs. 
Method 1: CAPM

$\mathrm{R}_{\mathrm{i}, \mathrm{t}}-\mathrm{R}_{\mathrm{f}, \mathrm{t}}=\alpha_{\mathrm{i}}+\beta_{\mathrm{i}} \mathrm{RMRF}_{\mathrm{t}}+\varepsilon_{\mathrm{i}, \mathrm{t}}$,

where $R_{i, t}$ is the return on insider portfolio $i$ in month $t, R_{f, t}$ is the risk-free return in month $t$, and $R M R F_{t}$ is the month $t$ value-weighted market return minus the risk-free rate. Here, $\alpha_{\mathrm{i}}$ can be interpreted as the abnormal return to portfolio $i$. Although research over the past 20 years has produced significant evidence against this unconditional version of the CAPM, it is still used for performance evaluation, both by academics and practitioners. ${ }^{19}$ Thus, it provides a good starting point for our analysis.

\section{Method 2: 4-Factor Model}

One problem for the unconditional CAPM is that it cannot explain differences in returns for portfolios sorted by stock characteristics such as size, past returns (momentum), or measures of "value" such as the price-to-earnings, cash-flow-to-price, and book-to-market ratios. ${ }^{20}$ Since Section 2 presented evidence that the purchase and sale portfolios differ from the market along size, momentum, and value dimensions, it is important that we adjust for these "strategies" in our analysis. The 4-factor model of Carhart (1997) is ideally suited for this purpose and has proved useful in several recent studies of performance evaluation. ${ }^{21}$ The model is estimated by

$$
\mathrm{R}_{\mathrm{i}, \mathrm{t}}-\mathrm{R}_{\mathrm{f}, \mathrm{t}}=\alpha_{\mathrm{i}}+\beta_{\mathrm{i}, 1} \mathrm{RMRF}_{\mathrm{t}}+\beta_{\mathrm{i}, 2} \mathrm{SMB}_{\mathrm{t}}+\beta_{\mathrm{i}, 3} \mathrm{HML}_{\mathrm{t}}+\beta_{\mathrm{i}, 4} \mathrm{PR} 1_{\mathrm{t}}+\varepsilon_{\mathrm{i}, \mathrm{t}}
$$

\footnotetext{
19 Examples of the CAPM's continuing role in performance evaluation are Malkiel (1995), Morningstar (1996), and Shirk et al. (1997).

20 See Basu (1977) (P/E ratio), Banz (1981) (size), Fama and French (1993) (size and book-to-market), Lakonishok, Shleifer and Vishny (1994) (several value measures), and Jegadeesh and Titman (1993) (momentum).

${ }^{21}$ See Carhart (1997), Chevalier and Ellison (1999), Daniel et. al (1997), and Metrick (1999).
} 
where $R_{i, t} R_{f, t}$, and $R M R F_{t}$ are defined as in (1). The terms $S M B_{t}$ (small minus big), $H M L_{t}$ (high minus low), and $P R 1_{t}$ (previous one-year return) are the month $t$ returns to zero-investment factor-mimicking portfolios designed to capture size, book-to-market, and momentum effects, respectively. ${ }^{22}$ While there is an ongoing debate about whether these factors are proxies for risk, we take no position on this issue and simply view the 4-factor model as a method of performance attribution. Thus, we interpret the estimated alphas as "abnormal returns" in excess of what could have been achieved by passive zero-cost investments in the factors.

Table 1 summarizes the factor returns over the January 1976 to December 1996 sample period. As would be expected, average returns are positive for all of the factors: 73 basis points a month for $R M R F, 25$ for $S M B, 39$ for $H M L$, and 87 for $P R 1$. It is striking that the momentum factor earns a higher average return than the market factor. Note that these factor returns ignore the transactions costs from their underlying trading strategies; such transaction costs would be considerable for the monthly turnover necessary for PR1. However, our insider purchase and sale portfolios also ignore transactions costs, and thus it is reasonable to measure their performance relative to costless strategies.

\section{Method 3: Characteristic-Selectivity (CS) Measure}

Our third measure of performance is the "characteristic-selectivity" (CS) measure developed by Daniel et al. (1997). This method matches each insider transaction to a portfolio of similar stocks, and then calculates an excess return relative to this portfolio on each day. This approach takes advantage of the transactions nature of the data, which substantially increases the

22 This model extends the Fama-French (1993) 3-factor model with the addition of a momentum factor. For details on the construction of the factors, see Fama and French (1993) and Carhart (1997). We are grateful to Mark Carhart for providing the factor returns. 
precision of abnormal return estimates under some circumstances. ${ }^{23}$ Though the procedure is conceptually straightforward, it is notationally cumbersome. We describe the basic idea here and cover the details in Appendix B.

To obtain the $C S$ measure, we begin by constructing 125 "bins" through independent $5 \times 5 \times 5$ sorts on size, book-to-market, and momentum quintiles. NYSE breakpoints are used for size and book-to-market, and combined NYSE/AMEX/Nasdaq breakpoints are used for momentum, with all NYSE/AMEX/Nasdaq stocks placed into quintiles on the basis of these breakpoints. Size and book-to-market sorts are performed once per year (on July 1), while momentum sorts are performed at the beginning of every month. Therefore, stocks can change bins every month. The three characteristics serve an analogous role to the $S M B, H M L$, and $P R I$ factors in the 4-factor model. In the CS approach, all stocks with the necessary data are allocated to a bin, which we call its "matching bin". ${ }^{24}$ Next, we calculate a daily value-weighted return for each bin. Then, for each of our insider portfolios, the monthly measure of abnormal returns is calculated as the return on a zero-investment portfolio that is long the insider portfolio and short a portfolio constructed using equivalent weights in the matching bins.

We write $R_{i, t}$ as the return to insider portfolio $i$ in month $t$ and $\operatorname{Bin}_{i, t}$ as the return to the matching bins of insider portfolio $i$ in month $t$. Then, the abnormal return to portfolio $i$ for that month, $C S_{i, t}$, is equal to the difference between these two returns: $C S_{i, t}=R_{i, t}-\operatorname{Bin}_{i, t}$. For the 252 months of the sample period, the overall performance measure, $C S_{i}$ is written as

\footnotetext{
${ }^{23}$ See Metrick (1999).

${ }^{24}$ Since some stocks must be excluded from this analysis because of a failure to match, the returns on the purchase and sale portfolios will be slightly different here than for the factor models. Appendix B, which discusses these issues, shows that any potential biases are small.
} 


$$
C S_{i}=\frac{\sum_{\operatorname{Jan} 76}^{\operatorname{Dec} 96} \mathrm{CS}_{\mathrm{i}, \mathrm{t}}}{252}
$$

In this setup, $C S_{i}$ is comparable to $\alpha_{i}$ from the factor models. Its statistical significance can be assessed by using the time-series standard error of $C S_{i, t}$.

The next two sections show that these three methods provide very similar results for the abnormal returns of insiders. There are additional methods, of course, that could be used to analyze returns, but no single analysis could employ all of them. ${ }^{25}$ We have no reason to believe that our results would be qualitatively different using other methods.

4. The Level and Timing of Insider Profits

A. Performance Evaluation of the Purchase and Sale Portfolios

This section applies each of the three performance-evaluation methods to the purchase and sale portfolios. In discussing the results, we use "performance measure" and "abnormal returns" as synonyms. The relationship of abnormal returns to "insider profits" are reversed between the purchase and sale portfolios. Since the purchase portfolio holds the stocks that insiders buy, a positive abnormal return implies positive insider profits. Conversely, since the sale portfolio holds the stocks that insiders sell, a negative abnormal return implies positive insider profits.

25 For example, we do not employ any conditional factor models such as in Eckbo and Smith's (1998) study of insider trading in Norway. We believe that the $C S$ approach addresses similar concerns as do conditional models, with the added advantage that it exploits the transactions nature of the data. 
Table 2 gives the results for the purchase portfolio. Under the CAPM, the purchase portfolio has a significant $\alpha$ of 47 basis points per month. ${ }^{26}$ The CAPM $\beta$ is 1.14 and is significantly greater than one. As we discussed in Section 2, insiders tend to purchase small stocks, value stocks, and those with low momentum. This strategy is also evident in the factor loadings (or "betas") from the 4-factor model, given in the third column of the table: positive and significant loadings on $S M B$ and $H M L$, and a negative and significant loading on PRI. In Table 1 , we saw that the average returns are positive for all of these factors, so while the positive loadings on $S M B$ and $H M L$ explain some of the abnormal performance observed in the CAPM, the negative loading on $P R I$ works in the opposite direction. Together, these factor loadings account for less than one-quarter of the abnormal return from the CAPM, and the 4-factor model $\alpha$ is a significant 37 basis points. Notice that the adjusted $R^{2}$ for the 4 -factor model is higher than for the CAPM (.92 vs. .79), and this added explanatory power results in a relatively large difference in the standard errors of the respective $\alpha$ estimates (16 vs. 11 basis points).

The $C S$ measure for the purchase portfolio is similar to those for the CAPM and the 4factor model, with a significant estimate of 41 basis points. Since the $C S$ measure is computed using a completely different method than are the alphas in the factor models, the similarity in results is reassuring. Taken together, the evidence from Table 2 shows that insiders earn economically large abnormal returns from their purchases, with point estimates ranging between 37 and 47 basis points per month. These results are consistent with evidence from studies that use intensive-trading criteria.

The results for the sales portfolio appear in Table 3. Here, all performance measures are economically small and statistically insignificant. The CAPM $\alpha$ is -9 basis points with a

26 Unless otherwise noted, "significant" refers to statistical significance at the five-percent level. 
standard error of 14 basis points. Recall that this portfolio is made up of insider sales, so negative values of $\alpha$ indicate that insiders are "profiting" by selling stocks that subsequently underperform; in this case, however, the profits are insignificant. The CAPM $\beta$ of 1.30 is significantly greater than even the CAPM $\beta$ from the purchase portfolio and indicates that insiders sell stocks with high fundamental risk. This high $\beta$ estimate explains why the sale portfolio can outperform the market in absolute terms (Figure 4), yet still earn negative abnormal returns under the CAPM.

For the 4-factor model, the loadings for the sale portfolio are different from those found for the purchase portfolio, with these differences consistent with our analysis in Section 2 and with the results of Rozeff and Zaman (1998). The loading on $H M L$ is negative and significant, suggesting a tilt toward growth stocks. The loading on $S M B$, while positive, is significantly lower than for the purchase portfolio. Interestingly, the loading on $P R 1$, while positive, is economically small and statistically insignificant. Thus, even though insiders tend to sell stocks that have recently increased in price, these stocks do not subsequently perform like other highmomentum stocks. With these loadings, the 4-factor model yields a positive but insignificant $\alpha$ of 5 basis points per month. For the $C S$ measure, the point estimate is an insignificant 6 basis points per month. Overall, there is no evidence that insiders earn abnormal returns in the sale portfolio. This is different from the typical finding in studies that use intensive-trading criteria; we reconcile this difference in Section 5.A. ${ }^{27}$

Overall, these results show that "outsiders" have little to fear from insiders, at least those who report their trades. Consider an outsider contemplating the sale of a stock to gain liquidity.

\footnotetext{
27 An exception is Lakonishok and Lee (1998), who find that stocks sold "most intensively" by insiders do not underperform.
} 
It is possible that this sale would be made to an insider, and insider purchases earn abnormal returns of about 500 basis points in the first year. However, since insiders purchase only about 0.03 percent of all stock (see Figure 1), her expected "costs" of trading against an insider are only 0.15 basis points. ${ }^{28}$ Thus, for a $\$ 10,000$ sale, she would be willing to pay about 15 cents to ensure that the trade did not have an insider as counterparty. This amount drops nearly to zero if the outsider were making a purchase from an insider. Although insiders make a much larger proportion of all sales ( 0.15 percent $)$ than purchases, than their abnormal returns on sales are small or nonexistent. Of course, there may be particular types of stocks or trades that lead to higher expected losses for outsiders. We deal with this issue further in Section 5.B.

\section{B. The Timing of Insider's Abnormal Returns}

We can better understand the dynamics of abnormal returns through a time decomposition of the purchase and sale portfolios. To illustrate this decomposition, consider the purchase portfolio. Recall that this shadow portfolio holds all insider purchases, using closing prices from their transaction dates, and keeps them in the portfolio for exactly one year. Now, we parse this strategy into portfolios that hold insider purchases for different subperiods during that year: day0-day5, day5-day21, day21-month6, and month6-year1. That is, when an insider trade first occurs, it is placed into the first portfolio (day0-day5); then, at the end of day 5, the purchase is removed from the first portfolio and placed into the second portfolio (day5-day21); etc. The days here are "trading days"; thus 21 days is approximately 1 month. We follow the same procedure to decompose the sale portfolio.

\footnotetext{
28 The calculation is $500 * .0003=.15$ basis points. To make this calculation, we assume that stocks sold to insiders subsequently outperform stocks sold to non-insiders by 5 percent. We do not argue that the insider trades somehow "cause" this edge in performance; rather, the point here is to provide another perspective on the expected value of the insiders' superior information.
} 
Table 4 shows annualized returns for each of these portfolios. For purchases, the annualized returns are higher than the market in each case. The day0-day5 portfolio, which contains all stocks purchased in the previous five days, earns annualized returns of 57.6 percent. Either insiders time their purchases well or the market is somehow finding out about these purchases and reacting to them. Somewhat surprising, however, are the returns earned by the day0-day5 sale portfolio. Since this portfolio holds stocks that insiders have sold over the previous five days, the high returns suggest insiders lose money relative to the market for the first five days after a sale.

For both purchases and sales, the same patterns over the first five days are repeated at smaller magnitudes over the subsequent 16 days, as can be seen from the day5-day21 results. After the first 21 days, purchases modestly outperform the market, whereas sales perform similarly to the market. To give more precise statements about performance, we turn to the performance-evaluation models.

Table 5 gives performance measures and standard errors for the day0-day5, day5-day21, day21-month6, and month6-year1 purchase and sale portfolios. The top panel gives the CAPM alphas, the middle panel gives the 4-factor alphas, and the bottom panel gives the $C S$ measures. The results confirm the significance of the patterns seen in Table 4. The day0-day5 purchase portfolio has highly significant positive point estimates across all models; these estimates range between 252 and 304 basis points per month. These returns illustrate the importance of using daily data to evaluate insider performance; any study that starts on report dates or uses only monthly data will miss this effect. These monthly abnormal returns translate into daily abnormal returns of about 13 basis points, or about 65 basis points over five trading days. Whether this is seen as economically "large" depends on the context. For example, the day0-day5 portfolio 
completely turns over every five trading days, far more often than any of the other portfolios studied in this paper. Assuming a one percent roundtrip transaction cost, the day0-day5 portfolio would incur approximately 400 basis points in transactions costs per month. Thus, the abnormal returns are not sufficient to allow a profitable trading strategy after transactions costs, even if such a trading strategy were otherwise feasible.

The purchase portfolio continues to earn abnormal returns well beyond 5 days. The day5-day21 portfolio earns significant abnormal returns of 129 basis points under the CAPM, 114 under the 4-factor model, and 136 for the $C S$ measure. For most insider transactions, more than 21 days pass before the transactions get reported and made public. The corresponding estimates for the day21-month6 portfolio are 54 basis points for the CAPM, 29 for the 4-factor model, and 36 for the $C S$ measure. Of these three estimates, all but the 4-factor $\alpha$ are significant. For the month6-year1 portfolio, all the point estimates are positive, but none is significant. The point estimates from Table 5 enable us to approximately decompose the overall abnormal returns to the purchase portfolio; using either the $C S$ measure or the 4-factor $\alpha$ as our guide, about threequarters of the total one-year return comes in the first six months, one-third comes in the first month, and one-sixth comes in the first five days. ${ }^{29}$

The most striking results of Table 5 are found for the day0-day 5 sale portfolio. The abnormal performance for this portfolio is positive and significant under all models, with point estimates ranging between 80 and 96 basis points per month. This is approximately equivalent to 4 to 5 basis points per trading day. While these results are consistent with the returns presented in Table 4, they still seem to be counterintuitive. Why would the stocks that insiders sell perform

\footnotetext{
29 The CS estimate for the overall purchase portfolio (Table 3) is 41 basis points per month, or approximately 492 basis points per year. Since the point estimate for the month6-year1 portfolio is 19 basis points, we attribute $19 * 6$ $=114$ of the total to the last six months. Similar calculations for the other horizons yield the estimates in the text.
} 
so well over the subsequent five days? In section 5.A, we present evidence to show that these short-horizon returns can be explained by the recovery from the price-depressing effect of highvolume insider sales. That is, they are largely a market microstructure effect.

At longer horizons, sale portfolios fail to earn significant abnormal returns, with the alphas and CS measures economically close to zero in most cases. Since our main sale portfolio, analyzed in Section 4.A, holds stocks for one year, the positive abnormal returns earned in the first five days do not noticeably change the overall results.

\section{A Closer Look at Insider Profits}

Thus far, we have confined our analysis to the aggregate purchase and sale portfolios. In this section, we decompose the purchase and sale portfolios along several dimensions: volume of the trade, size of the firm, insider's position in the firm, and whether the trade is executed directly for an insider or indirectly for another party. These subclasses have been studied using intensive-trading criteria and/or event-study methods, techniques that could aid other investors in forecasting future stock returns. Our analysis asks a different question - how much do insiders profit in each type of trade? - and thus uses performance-evaluation methods on value-weighted returns to answer it.

\section{A. The Volume of a Trade}

Are high-volume trades the most profitable? There are logical reasons to believe that the highest-volume trades would reflect the strongest insider beliefs about corporate performance. However, such trades may have other motivations. For example, insiders with sizeable corporate holdings may make high-volume sales for diversification or liquidity purposes; such sales may 
be motivated more by a desire to reduce risk or buy a new house than to increase returns. Also, high-volume purchases may be related to a quest for corporate control and its non-pecuniary benefits and may only partially be related to expectation of future returns. On a more cynical note, one might believe that high-volume trades are more likely to be scrutinized by the SEC, so that insiders who report trades on illegal "inside information" may wish to take lower profits, by reducing or splintering trades, in order to reduce the probability of detection. These factors all militate against finding the highest-volume trades to be the most profitable.

Past research has generally found a positive relationship between trade volume and insider profits, although this relationship may break down for the highest-volume trades. ${ }^{30}$ In this section, we reexamine this relationship through the lens of our portfolio-based approach. Thus, we are able to extend the analysis to include the daily returns immediately following the trades and analyzing these returns using performance-evaluation methods. Our approach also allows for a time-decomposition of returns similar to Section 4.B; this decomposition can then provide insight into the puzzling day0-day5 returns of the sale portfolio.

We begin by decomposing the purchase and sale portfolios by trade volume into "lowvolume", "medium-volume", and "high-volume" purchase and sale portfolios. To form these portfolios, we first calculate the fraction of firm equity traded in each transaction. For example, a purchase of 10,000 shares of a stock with 100 million shares outstanding would represent 0.01 percent of equity. Next, we sort all trades by these equity fractions, with purchases and sales ranked separately. Based on these rankings, we divide purchases and sales into thirds: "low", medium", and "high". This yields cutoffs of 0.004 and 0.028 percent for the purchase portfolios,

\footnotetext{
30 See Seyhun (1986), Pascutti (1996), and Seyhun (1998). Jaffe (1974) finds no difference between overall tests and tests restricted to high-volume trades, but this may be due to his sample of only the largest NYSE firms, where the trade-volume effect has been found to be weakest (Seyhun (1998)).
} 
and 0.010 and 0.048 percent for the sale portfolios. That is, all sales below 0.010 percent of firm equity are classified as "low-volume", above 0.048 percent are classified as "high-volume", and in-between as "medium-volume". ${ }^{31}$ For our purposes, this procedure offers two advantages over simpler classifications based on absolute measures such as the number of shares or dollars traded. First, the absolute measures are highly correlated with firm size, and analyses based on them might confound firm-size and trade-volume effects. Our use of equity fractions mitigates this problem. Second, our approach increases the chance that trades with a large "marketimpact" are classified as "high-volume". ${ }^{32}$ The importance of this property will be seen below.

The performance measures for the trade-volume portfolios are summarized in Table 6 . To compare estimates across the different portfolios, we estimate each model as a seeminglyunrelated-regression (SUR) for the six decomposed purchase and sale portfolios; this framework provides estimates for the covariance of the performance measures. ${ }^{33}$ The abnormal returns for the high-volume and medium-volume purchase portfolios are economically large and statistically significant on all tests, with magnitudes that are similar both to each other and to the overall purchase portfolio. The low-volume purchase portfolio earns considerably lower abnormal returns, although its 4-factor $\alpha$ and $C S$ measure are still positive and significant. Using covariance estimates from the SUR (not reported in Table 6), we find that the medium-volume purchase portfolio achieves significantly higher performance measures on all three tests than does the low-volume purchase portfolio. Differences between the high-volume and low-volume

\footnotetext{
31 We use the whole sample period to make these cutoffs, but this procedure - which looks forward as well as backward - should not introduce any bias in this case.

32 Trades could also be classified using dollar trading volume (rather than firm equity) in the denominator. Unfortunately, CRSP does not include volume data for Nasdaq firms until 1983, so this method is not feasible. 33 In our case, the SUR approach yields exactly the same point estimates and standard errors as would separate estimations, and provides the covariance estimates necessary for our comparisons. Another method to compare performance measures is to evaluate the returns to zero-investment strategies that are long in one portfolio (e.g. lowvolume purchases) and short in another (e.g. medium-volume purchases). The SUR and zero-investment approaches are mathematically equivalent.
} 
performance measures are significant at the ten-percent level on all tests. The overall results for the purchase portfolios are consistent with Seyhun's (1998) findings.

Performance measures for the sale portfolios are economically small and - with one exception - not statistically significant. Under the CAPM, the low-volume sale portfolio earns significant negative abnormal returns. The point estimate of -15 basis points is not economically large, but it is relatively precisely estimated. This precision derives from the well-diversified nature of the low-volume portfolio which, by construction, cannot be dominated by a small number of positions. Note that there is no significant relationship between trade volume and profits for insider sales on any of the tests: none of the performance measures is significantly different from any other.

The results of Table 6 can help us to reconcile our overall findings with those of other authors. Recall that our estimated abnormal returns for purchases (Table 2) are similar to those found in other studies. Since the medium-volume and high-volume portfolios comprise twothirds of all trades and also represent the vast majority of traded shares and traded value, they tend to dominate both our tests and the tests used by other authors. In contrast, the abnormal returns for our sale portfolios are close to zero, while most other studies find negative abnormal returns after sales. For tests based on the CAPM, these results are consistent with our findings. The low- and medium-volume sale portfolios both have negative abnormal returns, and the magnitude of these returns, while small, is similar to those found by other authors. The largetrade sale portfolio, however, has slightly positive (but insignificant) abnormal returns, and it is this portfolio that dominates our value-weighted analyses. Thus, a value-weighted approach finds no abnormal returns for sales. 
To shed light on the counterintuitive positive abnormal returns for the day0-day5 sale portfolio, we perform the same time decomposition for each trade-volume portfolio that we did in Section 4.B for the overall purchase and sale portfolios. Table 7 illustrates the returns to the low-, medium-, and high-volume purchase and sale portfolios for the day0-day5 subperiod. The table gives compelling evidence that the positive abnormal returns earned by the day0-day5 sale portfolio are entirely driven by the highest-volume transactions. The high-volume sale portfolio has positive and significant performance measures under all models, with point estimates ranging between 130 and 144 basis points. Conversely, the performance measures for the low-volume sale portfolio are negative and significant under all models; this is the direction that would be expected when insiders make information-driven trades. Our hypothesis is that the high-volume trades are driven primarily by liquidity or diversification motives, and that these big trades cause downward price pressure, so that the day0-day5 abnormal returns are positive while the market "bounces back" from this pressure. ${ }^{34}$ Since price pressure is small or nonexistent for mediumand low-volume trades, we do not observe the same positive abnormal returns for those portfolios. Since the high-volume trades dominate the value-weighted sale portfolio, they are capable of driving the perverse short-run effect. This market-microstructure effect does not prevent the high-volume purchase portfolio from earning positive returns; here, the information component of these purchases overcomes any possible microstructure effect on prices. ${ }^{35}$

\footnotetext{
34 This kind of volume-based autocorrelation is documented in Conrad, Hameed, and Niden (1994).

35 In addition, high-volume sales are bigger, on average, than high-volume purchases (see cutoffs given in Table 7), so the microstructure effect is likely to be smaller for the purchases than for sales.
} 


\section{B. Firm Size}

Several studies that use intensive-trading criteria and event-study methods show that insider trading is most profitable in small firms (Seyhun (1986) and (1998), Pascutti (1996), Lakonishok and Lee (1998)). This empirical finding is consistent with intuition. The smaller the firm, the easier it is for a single manager to know more relevant information. And since small firms receive less attention than large firms do from Wall Street analysts, the smaller the firm, the more likely that insiders hold an informational advantage over other market participants.

We analyze the relationship between firm size and insider returns by decomposing the purchase and sale portfolios. At the beginning of each month, we divide the stocks traded on the NYSE into thirds based on size (market value). We then use the cutoffs for these thirds to place all NYSE/AMEX/Nasdaq stocks into one of three categories: "small-firm", "medium-firm", and "large-firm". Each insider transaction is then placed into a portfolio on the day of the trade based on the size of the firm. This holding stays in the same portfolio for the full year, even if the firm crosses a size cutoff. This procedure results in six portfolios (three for purchases and three for sales).

We present the results in Table 8. As would be expected from the other results of this paper, none of the sale portfolios earn significant abnormal returns under any of the methods. The results are more interesting for the purchase portfolios. The small-firm purchase portfolio earns significant abnormal returns under all three methods, with point estimates ranging between 31 and 51 basis points per month. For the other purchase portfolios, only the large-firm portfolio earns significant abnormal returns on any test (32 basis points per month for the $C S$ measure). Nevertheless, the performance measures for the small-firm purchase portfolio are never significantly different from the corresponding measures for either the medium- or large-firm 
purchase portfolios. ${ }^{36}$ In fact, the biggest difference occurs under the CAPM (51 basis points for small-firm purchases vs. 5 basis points for large-firm purchases), and some of this is certainly attributable to the small-firm anomaly in the CAPM. ${ }^{37}$ Under the 4-factor model, the difference in abnormal returns between the small- and large-firm purchase portfolios drops by half (relative to the CAPM difference), and for the $C S$ measure it disappears completely. Thus, and not surprisingly, the marginal impact of firm size on insider profits is considerably smaller (or nonexistent) once we control for size-related return anomalies. ${ }^{38}$ These results are not driven by our use of only three size portfolios: there remains no significant difference between the performance measures (4-factor alphas and CS measures) of the smallest and largest purchase portfolios even if we use five or ten size groupings. ${ }^{39}$

While there is no significant difference in abnormal returns among the trade-size portfolios, the probability of selling to an insider is much higher for small stocks ( 0.14 percent) than for large ones ( 0.02 percent). Using the $C S$ measure as our guide, an outsider making a sale of a small stock faces an expected loss of 0.43 basis points due to the possibility he is trading with an insider. While this is hardly monumental, it is approximately seven times higher than the equivalent expected cost when trading in large stocks.

\section{Insider's Position within the Firm}

Some insiders are more "inside" than others. The chief executive, for example, is likely to have better information about the firm's prospects than do lesser officers. Of course, since the CEO's trades are likely to be carefully scrutinized, both by shareholders and by regulators, he

\footnotetext{
36 This comparison uses covariances of the performance measures (not reported in the table) estimated by SUR. 37 See Banz (1981) and Fama and French (1993).

38 This same point is made by Rozeff and Zaman (1988), although their focus is on returns that can be earned by outsiders following the publication of insider trading data.

39 These results are available from the authors.
} 
may be more reluctant to trade on his informational advantage. The net effect of these considerations on the profitability of insider trading is an empirical question. Seyhun (1986 and 1998) analyzes the relationship between insiders' positions in their firms and the profitability of their trades, and concludes that there is an "information hierarchy", with top executives at the top, other officers in the middle, and directors at the bottom. In this section we study this information hierarchy using performance-evaluation methods applied to value-weighted portfolio returns.

We begin by decomposing the purchase and sale portfolios based on the job title of the insider. "Top executives" are chief executives, chairmen of the board, and presidents. "Officers" include all corporate officers except for top executives. "Directors" are members of the corporate board who are not also officers. These categories do not overlap, and they cover all trades in our sample. ${ }^{40}$ This decomposition results in three purchase portfolios and three sale portfolios. The top-executive purchase portfolio constitutes 10.0 percent of the total purchase portfolio, the officer-purchase portfolio 20.5 percent, and the director-purchase portfolio 69.5 percent. For sales, top-executives constitute 12.7 percent, officers 41.7 percent, and directors 45.6 percent.

The performance measures for these portfolios are summarized in Table 9. We estimate each model as a SUR so that performance estimates can be compared across portfolios. None of the sale portfolios earn significant abnormal returns on any of the tests. As usual, the purchase portfolios offer more varied results. The officer-purchase and director-purchase portfolios have significant abnormal returns under all tests, with point estimates close to those found for the

\footnotetext{
40 These definitions differ slightly from Seyhun's (1998), which do allow for overlap. Some insiders do not fit into any of these categories. We exclude them from the beginning; they are not represented in the purchase and sale portfolios. Please see Appendix A.
} 
overall purchase portfolio. Surprisingly, the top-executive purchase portfolio does not earn significant abnormal returns under any of the tests; however, while these point estimates are always below those for the officer-purchase and director-purchase portfolios, they never differ from them significantly. Thus, we cannot conclude that top executives do worse with their purchases than do officers or directors.

The difference between equal- and value-weighted analyses allows us to reconcile our results with Seyhun's. The trades of top executives are about twice as big, on average, as those of officers and directors. Also, top executives are responsible for a disproportionate number of the very largest purchases. If the abnormal returns to purchases fall off for the very largest trades, then all of the results are consistent. ${ }^{41}$ We do not adjust for the interaction of trade volume with insider type because that is not the purpose of our analysis; if top executives trade in highervolume blocks than other insiders, we view this decision as a conscious choice of how they use their information, and we are only interested in the net result on their profits.

The results of this section demonstrate why a value-weighted, portfolio-based analysis provides an important perspective on insider trading. Seyhun's results are important for outsiders seeking to profit from the information content of insider trades; he shows that the trades of top executives, whether equally-weighted or conditional on trade size, are more informative about future returns than are the trades of other insiders. Our results are important to regulators, and to outsiders who may be trading with insiders. We show that, unconditionally, a dollar traded by a top executive earns no higher return than a dollar traded by another insider.

\footnotetext{
41 Seyhun's (1998) analysis uses many categories of trade volume to search for the most informative trades about future returns. He finds a concave relationship between trade volume and abnormal returns, with abnormal returns falling off for the very highest trades. Our analysis in Section 5.A. found medium-volume purchases earning the same abnormal returns as large-volume purchases. This is consistent with the concave relationship found by Seyhun.
} 


\section{Direct vs. Indirect Ownership of Shares}

Insider's holdings can be subdivided into two broad categories. "Direct" holdings are held in the insider's name. "Indirect" holdings are held in the name of another person, where the corporate insider has a pecuniary interest, by reason of any contract, understanding, or relationship. ${ }^{42}$ With the exception of Pascutti (1996), past studies of insider trading have not distinguished between these two types of ownership.

In this section, we divide the sale and purchase portfolios into their direct and indirect components. Thus, the direct-purchase portfolio contains all purchases for direct holdings made over the previous year; the other portfolios are indirect-purchases, direct-sales, and indirect-sales. The direct portfolios comprise the majority of both the purchase and sales portfolios, but the indirect portfolios are still substantial, comprising 41.5 percent of the sale portfolio and 21.9 percent of the purchase portfolio.

It is not obvious what to expect for the relative performance of direct and indirect portfolios. For direct trades, insiders are likely to exercise total discretionary control and keep all the proceeds. In many indirect trades, insiders exercise considerably less discretion and have smaller personal incentives. This suggests that direct trades would be more likely to reflect insider information and yield higher profits.

However, insiders make many of their direct trades - particularly those of high volume to diversify their portfolios or gain more control of the corporation. Indirect trades, on the other hand, are less likely to be driven by considerations of control or diversification, especially since indirect holders usually do not have their human capital invested in the firm. Similarly, purchases designed to increase control are probably more likely for a direct holding than for an

\footnotetext{
${ }^{42}$ See Goodman (1991).
} 
indirect one. Since these considerations are stronger for high-volume transactions, they have the potential to dominate a value-weighted analysis. This reasoning suggests that profits will be higher for indirect trades than for direct ones.

Table 10 summarizes the evidence for the direct and indirect purchase and sale portfolios. Once again, we estimate each model as a SUR so that the performance estimates can be compared across portfolios. The CAPM $\alpha$ for the direct-purchase portfolio is 60 basis points; the corresponding $\alpha$ for the indirect-purchase portfolio is 43 basis points. These point estimates are significantly different from zero, but not from each other. The 4-factor alphas and CS measures show a similar pattern. The direct-purchase portfolio earns a 4-factor $\alpha$ of 51 basis points and a $C S$ measure of 60 basis points, both of which are significant. The indirect-purchase portfolio has a 4 -factor $\alpha$ of 34 basis points and a $C S$ measure of 31 basis points, but only the former measure is significant. For each of the three tests, the performance measure for the directpurchase portfolio has a higher point estimate than the corresponding measure for the indirectpurchase portfolio, but the difference is never significant. For the direct-sales and indirect-sales portfolios, all of the performance measures are economically small and statistically insignificant. Overall, there is no conclusive evidence of differential profits between direct and indirect trades.

\section{Conclusion}

There are three good reasons to study the profitability of trades by corporate insiders: science, profit, and policy. Science examines the implications of the findings for market efficiency. Profit hopes to develop optimal trading strategies, following the actions of insiders. 
Policy seeks to determine the effectiveness of insider trading rules, and the implications of insider profitability for both fairness and market performance.

Our analysis focused on science and policy. It began with the central question: How much do insiders profit when they trade stock in their own firms? To address this question, we employed performance-evaluation methods that analyze value-weighted portfolios comprised of all insider trades. This approach - new to the insider trading literature - enables us to compute any abnormal returns earned by insiders.

Insiders profit handsomely from their purchases, but not at all from their sales. This is not surprising. Insider purchases likely reflect favorable information. Insider sales, by contrast, are often made from shares received as part of executive compensation. Therefore, these sales may be undertaken to gain liquidity or diversify holdings, implying little information content. Given the sources and motivations of insiders' sales, it is not surprising that their dollar volume is nearly eight times that of purchases.

Insiders' transactions differ from the market as a whole. Insiders disproportionately purchase shares in small firms, value firms, and those that have recently underperformed. Their sales are made mainly in growth firms that have experienced high recent returns. To correct for differences in returns that may be driven entirely by these distinctive characteristics of insider transactions, we calculated abnormal returns using three different performance-evaluation methods. Under all three methods, the story is much the same. The abnormal returns to a valueweighted portfolio of all insider purchases—-holding positions for one year—are roughly 40 basis points per month, an economically and statistically significant magnitude. The first five days after purchase yield approximately one-sixth of the abnormal return, and one-third comes within the first month. This evidence suggests that insider buyers have a good feel for near-term 
developments within their firm, or that actions by others who follow their trades move the market. None of our methods find that insider sales reap profits.

Our performance-evaluation methods can readily determine whether particular types of trades do better or worse. Thus, we look at profitability by firm size, the dollar volume of the transaction, and the insider's position within the firm. We find that the trades of top executives do no better than those of their less lofty peers. Similarly, firm size does not affect the profitability of insider trading. However, low-volume purchases are less profitable than those of higher-volume. We made no attempt to look at the potential for profitably following insiders' trades; other methods are better suited to that investigation, and the prior literature has covered them well.

What should policy makers think of our results? Surely insiders have valuable information. If they do, only a Draconian regulatory system could prevent them from trading profitably, and the evidence shows that the existing system does not. Policy makers can be reassured, however, that the system is sufficiently effective -- presumably by holding down both the volume and profitability of insider trades -- that outsiders are not significantly disadvantaged when selling stock on the open market, and they are not disadvantaged at all when buying. Inside purchases comprise just $0.02 \%$ of all purchases on the open market; on average, outsiders lose just 15 cents on a $\$ 10,000$ sale because an insider may be on the other side. But in circles where this happy information is not widely known, investors with inflated perceptions of their disadvantage may still be reluctant to trade.

Our principal accomplishment in this paper was to quantify the tilt in the playing field enjoyed by insiders. Due to the disparity of numbers between insiders and outsiders, what appears as an easy downward slide for the insiders produces an imperceptible upward tilt for 
those who must trade against them. Inside traders are like ace handicappers at the racetrack.

They profit nicely, but only by imposing tiny losses on the masses. The question of fairness falls to the eye of the beholder. 


\section{References}

Bainbridge, Stephen, 1998, Insider Trading, forthcoming in the Encyclopedia of Law \& Economics.

Banz, Rolf, 1981, The relation between return and market value of stocks, Journal of Financial Economics 38, 269-296.

Barber, Brad M. and John D. Lyon, 1997, Detecting long-run abnormal stock returns: The empirical power and specification of test statistics, Journal of Financial Economics 43, 341-372.

Barber, Brad M., John D. Lyon, and Chih-Ling Tsai, 1999, Improved methods for tests of longrun abnormal stock returns, forthcoming in the Journal of Finance.

Barclay, Michael J. and Jerold B. Warner, 1993, Stealth trading and volatility: Which trades move prices? Journal of Financial Economics 34, 281-305.

Basu, Sanjoy, 1977, The investment performance of common stocks in relation to their price-toearnings: A test of the efficient markets hypothesis, Journal of Finance 32, 663-682.

Brav, Alon and Paul Gompers, 1997, Myth or reality: The long-run underperformance of initial public offerings: Evidence from venture and nonventure capital-backed companies, Journal of Finance 52, 1791-1822.

Carhart, Mark, 1997, On persistence in mutual fund performance, Journal of Finance 52, 57-82.

Chan, Louis K.C, Narasimhan Jegadeesh and Josef Lakonishok, 1995, Evaluating the performance of value versus glamour stocks: The impact of selection bias, Journal of Financial Economics 38, 269-296.

Conrad, Jennifer, A. Hameed, and C. Niden, 1994, Volume and autocovariances in short-horizon individual security returns, Journal of Finance 49, 1305-1329.

Daniel, Kent, Mark Grinblatt, Sheridan Titman, and Russ Wermers, 1997, Measuring mutual fund performance with characteristic based benchmarks, Journal of Finance 52, 1035-1058.

Eckbo, B. Espen and David C. Smith, 1998, The conditional performance of insider trades, Journal of Finance 53, 467-498.

Fama, Eugene F. and Kenneth R. French, 1993, Common risk factors in the returns on bonds and stocks, Journal of Financial Economics 33, 3-53.

Finnerty, J. E., 1976, Insiders and market efficiency, Journal of Finance 31, 1141-1148.

Gompers, Paul and Josh Lerner, 1998, Venture Capital Distributions: Short-Run and Long-Run Reactions, Journal of Finance 53, 2161-2183. 
Goodman, Amy L., 1991, A Practical Guide to Section 16: Reporting and Compliance, Prentice Hall Law \& Business.

Jaffe, Jeffrey F., 1974, Special information and insider trading, Journal of Business 47, 410-428.

Jegadeesh, Narasimhan and Sheridan Titman, 1993, Returns to buying winners and selling losers: Implications for stock market efficiency, Journal of Finance 48, 65-91.

Jeng , Leslie A., 1998, Corporate insiders, market makers, and the window of opportunity, working paper, Boston University.

Hall, Brian and Jeffrey B. Liebman, 1998, Are CEOs really paid like bureaucrats?, The Quarterly Journal of Economics 113, 653-692.

Kothari, S.P. and Jerold B. Warner, 1997, Measuring long-horizon security price performance, Journal of Financial Economics 43, 301-339.

Lakonishok, Josef and Inmoo Lee, 1998, Are insiders' trades informative?, NBER Working Paper No. 6656.

Lakonishok, Josef, Andrei Shleifer, and Robert Vishny, 1994, Contrarian investment, extrapolation, and risk, Journal of Finance 49, 1541-1578.

Lin, Ji-Chai and John S. Howe, 1990, Insider trading in the OTC market, Journal of Finance 45, 1273-1284.

Lorie, James H., and Victor Niederhoffer, 1968, Predictive and statistical properties of insider trading, Journal of Law and Economics 11, 35-53.

Loughran, Tim and Jay Ritter, 1995, The new issues puzzle, Journal of Finance 50, 23 - 52.

Malkiel, Burton, 1995, Returns from investing in mutual funds 1971 to 1991, Journal of Finance 50, 549-572.

Metrick, Andrew, 1999, Performance evaluation with transactions data: The stock selection of investment newsletters, forthcoming in the Journal of Finance.

Meulbroek, Lisa K., 1992, An empirical analysis of illegal insider trading, Journal of Finance 47, 1661-1699.

Morningstar, 1996, Ascent database, April.

Pascutti, Michael J., 1996, Three Essays in Finance: Informed Trading on Nasdaq, Contrarian Trading by Insiders, and Swap Pricing, Ph.D. dissertation, Harvard University. 
Rozeff, Michael S. and Mir A. Zaman, 1988, Market efficiency and insider trading: New evidence, Journal of Business 61, 25-44.

Rozeff, Michael S. and Mir A. Zaman, 1998, Overreaction and insider trading: evidence from growth and value portfolios, Journal of Finance 53, 701-716.

Seyhun, H. Nejat, 1986, Insiders' profits, costs of trading and market efficiency, Journal of Financial Economics 16, 189-212.

Seyhun, H. Nejat, 1988, The information content of aggregate insider trading, Journal of Business 61, 1-24.

Seyhun, H. Nejat, 1992, Why does aggregate insider trading predict future stock returns? Quarterly Journal of Economics 107, 1303-1331.

Seyhun, H. Nejat, 1998, Investment Intelligence from Insider Trading, MIT Press.

Shirk, George S. III, Julie Cuenca and Greg Carlson, 1997, Platinum fund\$, Mutual Funds October, 87.

Appendix A - Data Issues

Form 4 must be filed with the SEC within ten days following the end of each month in which there is a change in direct or indirect insider ownership. Among the information required on Form 4 are: name and address of reporting person, issuer name and ticker or trading symbol, relationship of reporting person to the issuer (i.e., officer, director, etc.), filing date, type of security traded, transaction date (month/day/year), transaction code (e.g., open-market transaction, private transaction, transaction under an employee stock ownership plan), number of equity securities traded, per share price of equity securities, ownership form (direct or indirect) ${ }^{43}$

We restrict our study to open-market transactions in equity securities that have data available from the Center for Research in Securities Prices (CRSP). Over the January 1, 1975, to December 31 , 1996, sample period, there were 899,146 open-market transactions $(386,102$

43 Goodman (1991). 
purchases and 513,044 sales). ${ }^{44}$ Of this number, 17,340 (1.9 percent) have missing transaction dates, leaving 881,806 . We next purged duplicate transactions from this total. We defined a duplicate as a transaction with identical data in all categories. We believe these duplicates can occur for many innocuous reasons. This step removes 57,145 (6.5 percent) and leaves 824,661. Prior to May 1991, Form 4 distinguished between open-market purchases and sales (transaction codes $\mathrm{P}$ and $\mathrm{S}$ ) and private transactions (transaction codes $\mathrm{J}$ and $\mathrm{K}$ ). During this period, open-market transactions outnumber private transactions by a ratio of about 11 to 1 . After May 1991, private transactions use the same codes as open-market transactions. Ideally, we would exclude private transactions from our database; these transactions may take place with restricted securities, the counterparty often knows he is trading with an insider, and the trade is much more likely to be executed for liquidity or diversification motives than are open-market transactions. Therefore, we do not include any private transactions prior to May 1991, and we use several filter rules, discussed below, to eliminate the largest private transactions after this date. These same filter rules also serve to purge the data of obvious coding errors.

Our first filter is to remove all transactions where the shares traded exceed trading volume for that day. Since private transactions would not be included in the exchange traded volume of the day, this filter is likely to catch many of the largest post-1991 private transactions. This results in the loss of 4,030 transactions ( 0.5 percent) and leaves us with 820,631 . Our second filter purges all transactions whose prices fall outside the daily trading range reported on CRSP. We call these "bad prices". There are many reasons that bad prices can occur: a private transaction may be executed outside of the range; the date, price, or transaction type may be miscoded by the insider; input error may be made by the data provider, etc. The frequency of

\footnotetext{
${ }^{44}$ For transaction dates after May 1991, there are also some private transactions in our data set. Our methods for disentangling these trades from open-market transactions are discussed below.
} 
these problems, given below, is high enough to dissuade us from using the reported transaction prices in our analysis. Furthermore, most of the reasons given for bad prices would also render the transaction unsuitable for inclusion in the purchase and sale portfolios, even using the closing prices.

Our analysis suggests that the majority of transactions with "bad prices" are due to miscodes of the date (either by the insider or the data provider). Our procedure necessitates that we first purge all transactions where CRSP provides no information on the trading range. This results in a loss of 35,431 transactions (4.3 percent). Of the remaining 785,200 transactions, 221,337 (28.2 percent) have bad prices. To see how many of these may be due to simple miscodes of the date (perhaps because the filing date is miscoded as the trading date), we calculate a trading range beginning on the first day of the previous month and extending until the last day of the current month. Out of 221,337 trades with bad prices, 163,141 (73.7 percent) fall within this extended trading range. The remaining 58,196 trades with bad prices are likely to be private transactions not caught in the previous filter, and other miscodes by the insider or the data provider. Our final data set includes 563,863 transactions $(214,897$ purchases and 348,966 sales).

These filters have not caught all possible errors in the data. For example, any miscoded dates that do not have bad prices will remain in the data set. Since such trades must necessarily be in stocks with small price changes around the transactions, they are likely to bias our abnormal returns toward zero. Our diagnostic tests suggest that the value-weighted fraction of such bad trades is likely to be small and should not cause qualitative changes in our results. Similarly, some private transactions will escape the filters. Since our filters would have caught about 72 percent of the private transactions before May 1991, and the ratio of private 
transactions to open-market transactions is small, we doubt that the remaining private transactions would cause qualitative changes in our results.

Appendix B - The Characteristic-Selectivity (CS) Measure

This appendix provides the details for the computation of the $C S$ measure described in Section 3. This measure is based on the methodology of Daniel et al. (1997). For each insider transaction portfolio, the monthly measure of abnormal returns is calculated as the return on a zero-investment portfolio that is long in the insider transaction portfolio and short in a portfolio constructed using equivalent weights in the matching bins. In effect, one just combines the monthly abnormal returns for each stock in the portfolio.

The assumption underlying this model is that all stocks in the same bin have exactly the same expected return. If this assumption is satisfied, then the performance measure will have a zero expected return at all times. Thus, the insider portfolios that shift their portfolio composition conditional on expected factor realizations will have no bias in their estimated performance measure.

A more formal description of the methodology is:

$\mathrm{d} \in \mathrm{t}$ : the set of all days $\mathrm{d}$ in month $\mathrm{t}$, $\mathrm{s} \in \mathrm{i}$ : the set of all stocks s held by portfolio $\mathrm{i}$, $\mathrm{b}(\mathrm{s})$ : bin $\mathrm{b}$ matched to stock $\mathrm{s}$, $\mathrm{R}_{\mathrm{s}, \mathrm{d}}=$ net return for stock s on day $\mathrm{d}$, $\mathrm{R}_{\mathrm{b}(\mathrm{s}), \mathrm{d}}=$ net return for bin $\mathrm{b}$ matched to stock s on day $\mathrm{d}$, and $\mathrm{W}_{\mathrm{s}(\mathrm{i}), \mathrm{d}}=$ weight placed on stock s by portfolio i on day $\mathrm{d}$.

Using this notation, the $C S$ measure for each month, $C S_{i, t}$, is then calculated as

$$
\mathrm{CS}_{\mathrm{i}, \mathrm{t}}=\prod_{\mathrm{d} \in \mathrm{t}}\left(1+\sum_{\mathrm{s} \in \mathrm{i}}\left(\mathrm{W}_{\mathrm{s}(\mathrm{i}) \mathrm{d}} * \mathrm{R}_{\mathrm{s}, \mathrm{d}}\right)\right)-\prod_{\mathrm{d} \in \mathrm{t}}\left(1+\sum_{\mathrm{s} \in \mathrm{i}}\left(\mathrm{W}_{\mathrm{s}(\mathrm{i}) \mathrm{d}} * \mathrm{R}_{\mathrm{b}(\mathrm{s}), \mathrm{d}}\right)\right)
$$


where $\sum_{\mathrm{s} \in \mathrm{i}}\left(\mathrm{W}_{\mathrm{s}(\mathrm{i}), \mathrm{d}} * \mathrm{R}_{\mathrm{s}, \mathrm{d}}\right)$ is the actual net return for portfolio $i$ on day $d$ and $\sum_{\mathrm{s} \in \mathrm{i}}\left(\mathrm{W}_{\mathrm{s}(\mathrm{i}), \mathrm{d}} * \mathrm{R}_{\mathrm{b}(\mathrm{s}), \mathrm{d}}\right)$ is the net return that would be achieved on day $d$ if all funds were invested in the matching bins. The $C S_{i}$ measure (Equation 3) is then calculated as the mean of the monthly $C S_{i, t}$ measures.

Not all stocks will be included in the $C S$ calculation; if a stock cannot be matched to a bin, then it is not included in the test. The two main reasons for a failure to match are, first, insufficient past returns for a momentum calculation and, second, the absence of a book-equity observation in COMPUSTAT. Both of these data requirements lead to new issues being deleted from the portfolios. To the extent that new issues underperform similar stocks, this causes an upward bias in the estimated selectivity performance measure. ${ }^{45}$ If such an upward bias exists, it does not seem to have a significant effect on the results. For example, when we repeat the CAPM and 4-factor tests of Tables 2 and 3 using returns calculated only from stocks that have bin assignments, then the results are almost identical: the CAPM $\alpha$ is 45 basis points for purchases (two points lower than the corresponding $\alpha$ of 47 basis points in Table 2) and -9 basis points for sales (exactly the same as the corresponding $\alpha$ in Table 3); the 4-factor $\alpha$ is 42 basis points for purchases (five points higher than the corresponding $\alpha$ of 37 basis points in Table 2) and nine basis points for sales (four basis points higher than the corresponding $\alpha$ of five basis points in Table 3).

45 See Loughran and Ritter (1995) and Brav and Gompers (1997) for evidence on the new-issues bias. On a "binadjusted" basis, Brav and Gompers' (1997) work suggests that this bias should not be large. See also Chan, Jegadeesh, and Lakonishok (1995) for a discussion of the bias induced by omitting stocks that do not have data in COMPUSTAT. 
Figure 1

\section{Percentage of Market Volume Traded by Insiders}

This figure plots insiders' purchases and sales as a percentage of market volume for each month of the sample period. The percentage is calculated as the total value in all securities of insider purchases (sales) for that month divided by the total value of all monthly trading on NYSE, AMEX, and Nasdaq. The average percentages across the whole sample are 0.03 percent for purchases and 0.22 percent for sales.

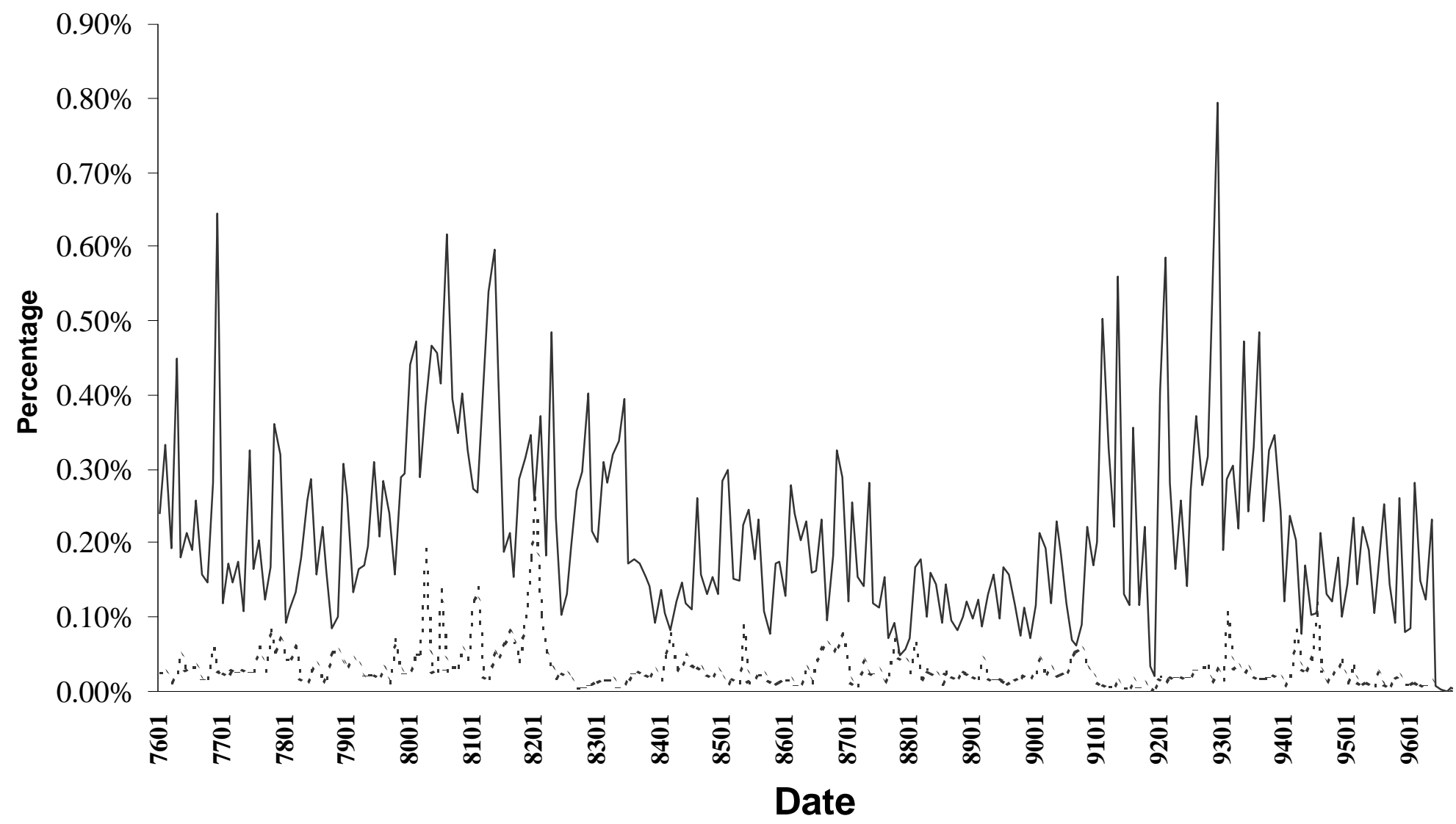




\section{Figure 2}

\section{Cumulative Abnormal Returns Measured from the Date of Insider Transactions}

This figure plots the average cumulative abnormal return (CAR) measured from the date of insider purchase and sale transactions. Daily abnormal returns are defined here as a stock's return minus the value-weighted market return. These daily abnormal returns are calculated for the day of the transaction (day 0) and for each of the 100 days before and after the transaction. The CAR for day $-t$ is the sum of daily abnormal returns beginning on day $-t$ and ending on day 0 . The CAR for day $t$ is the sum of the daily abnormal returns beginning on day 0 and ending on day t. This procedure yields a time-series of CARs for each insider purchase and sale; these CARs are averaged across all purchases and sales to produce the figure. The sample is for transactions from January 1, 1975 to December 31, 1996.

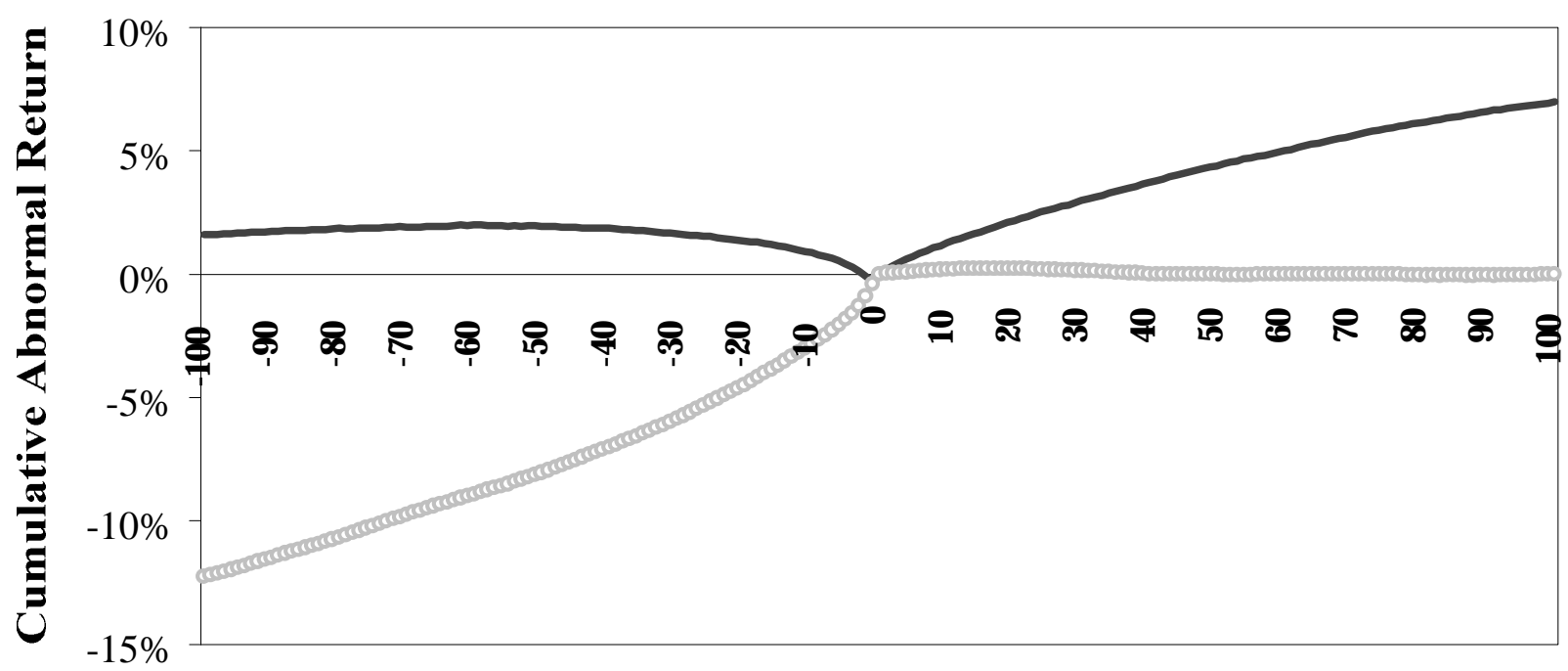

Day

- Purchase CAR $\stackrel{-}{-}$ Sale CAR 


\section{Figure 3}

\section{Insider Purchase and Sale Portfolios as a Percentage of Total Market Capitalization}

This figure shows the percentage of the market held in our insider purchase and sale portfolios. The purchase (sale) portfolio includes all shares purchased (sold) by insiders over the previous year. On each day, we calculate the percentage of the total market value (NYSE/AMEX/Nasdaq) held in each of these portfolios. Monthly percentages are expressed as the mean of the daily percentages from that month; these monthly percentages are then plotted in the figure. For the sample period of January 1, 1976 to December 31,1996 , the averages of these monthly percentages are 0.02 percent for purchases and 0.11 percent for sales.

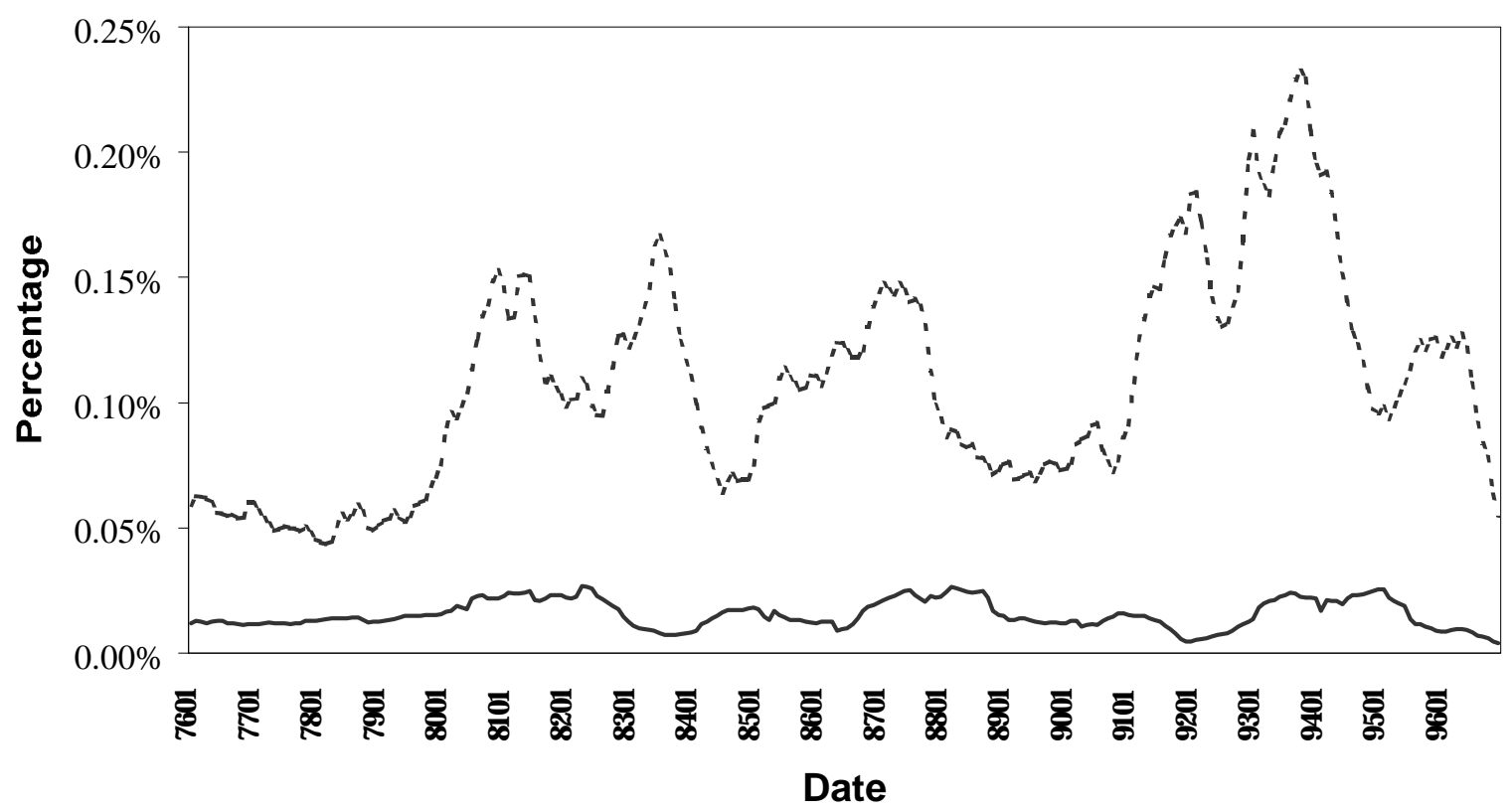

Purchase - - - Sale 


\section{Figure 4}

\section{Returns to Purchase and Sale Portfolios}

This figure plots the value of a hypothetical \$1 investment on January 1, 1976, in the purchase portfolio, sale portfolio, and the value-weighted market. The purchase (sale) portfolio includes all shares purchased (sold) by insiders over the previous year. The value-weighted market includes all NYSE, AMEX, and Nasdaq firms. The annualized returns to these portfolios are 23.0 percent for purchases, 16.4 percent for sales, and 15.6 percent for the value-weighted market.

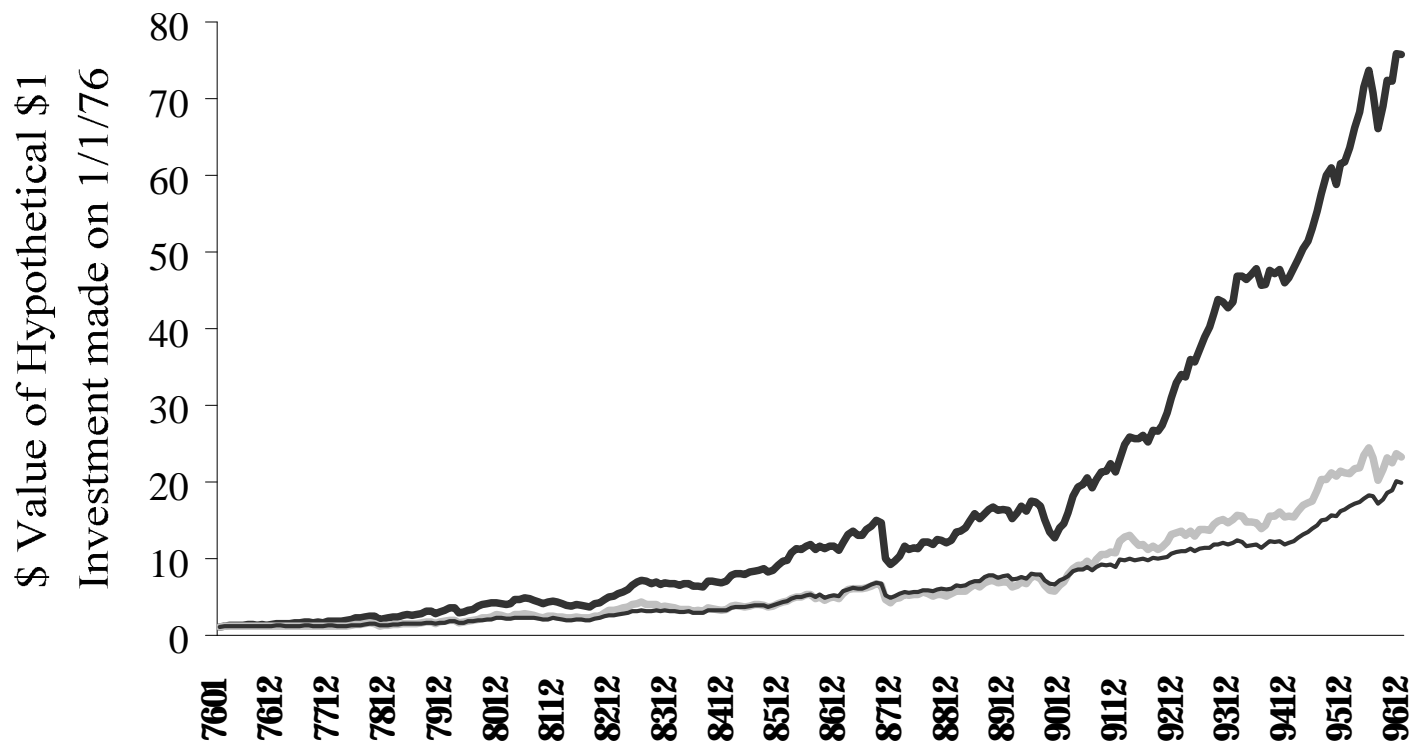

Date

- Purchase - Sale - Market




\section{Table 1}

\section{Summary Statistics of Factor Returns}

This table provides summary statistics for the factors used in the CAPM (equation 1) and the 4-factor model (equation 2). These factors - RMRF, SMB, HML, and PR1 represent the returns to zero-investment portfolios designed to capture market, size, bookto-market, and momentum effects, respectively. (Consult Fama and French (1993) and Carhart (1997) on the construction of these factors.) The sample is from January 1, 1976 to December 31, 1996.

\begin{tabular}{lcccc}
\hline Factor & Mean & Std. Dev. & Minimum & Maximum \\
\hline RMRF & $0.73 \%$ & $4.27 \%$ & $-22.77 \%$ & $12.68 \%$ \\
SMB & 0.25 & 2.53 & -9.79 & 9.06 \\
HML & 0.39 & 2.53 & -8.49 & 8.92 \\
PR1 & 0.87 & 2.81 & -10.65 & 10.02 \\
\hline
\end{tabular}




\section{Table 2}

\section{Performance-Evaluation Results for Purchase Portfolio}

This table presents the performance-evaluation results for the purchase portfolio. The purchase portfolio includes all shares purchased by insiders over the previous year. Column 2 gives the results for the CAPM (equation 1). Column 3 gives the results for the 4-factor model (equation 2). Column 4 gives the results for the CS measure (equation 3). For the factor models, $\alpha$ is the regression intercept, and the next four rows give coefficients and standard errors (in parentheses) for the independent variables: RMRF, SMB, HML, and PR1. These independent variables are the returns to zero-investment portfolios designed to capture market, size, book-to-market, and momentum effects, respectively. (Consult Fama and French (1993) and Carhart (1997) on the construction of these factors.) The symbols * and ** indicate two-tail significance at the five-percent level and at the onepercent level, respectively. The bottom row of the table provides the $\mathrm{R}^{2}$ for the factor regressions. The sample is from January 1, 1976 to December 31, 1996.

\begin{tabular}{cccc}
\hline & CAPM & 4-Factor & CS Measure \\
\hline & & & \\
& $0.0047^{* *}$ & $0.0037^{* *}$ & \\
RMRF & $(0.0016)$ & $(0.0011)$ & \\
& $\left(0.1418^{* *}\right.$ & $1.0980^{* *}$ & \\
& & $(0.0272)$ & \\
SMB & & $0.7379^{* *}$ & \\
& & $(0.0416)$ & \\
HML & & $0.1641^{* *}$ & \\
& & $(0.0450)$ & \\
PR1 & & $-0.1273^{* *}$ & \\
& & $(0.0380)$ & $0.0041^{* *}$ \\
CS & & & \\
& & & \\
\hline $\mathbf{R}^{2}$ & 0.7919 & 0.9153 & \\
\hline
\end{tabular}




\section{Table 3}

\section{Performance-Evaluation Results for Sale Portfolio}

This table presents the performance-evaluation results for the sale portfolio. The sale portfolio includes all shares sold by insiders over the previous year. Column 2 gives the results for the CAPM (equation 1). Column 3 gives the results for the 4-factor model (equation 2). Column 4 gives the results for the CS measure (equation 3). For the factor models, $\alpha$ is the regression intercept, and the next four rows give coefficients and standard errors (in parentheses) for the independent variables: RMRF, SMB, HML, and PR1. These independent variables are the returns to zero-investment portfolios designed to capture market, size, book-to-market, and momentum effects, respectively. (Consult Fama and French (1993) and Carhart (1997) on the construction of these factors.) The symbols * and ** indicate two-tail significance at the five-percent level and one-percent level, respectively. The bottom row of the table provides the $\mathrm{R}^{2}$ for the factor regressions. The sample is from January 1, 1976 to December 31, 1996.

\begin{tabular}{cccc}
\hline & CAPM & 4-Factor & CS Measure \\
\hline & & & \\
& -0.0009 & 0.0005 & \\
& $(0.0014)$ & $(0.0010)$ & \\
RMRF & $1.2985^{* *}$ & $1.1171^{* *}$ & \\
& $(0.0319)$ & $(0.0235)$ & \\
SMB & & $0.5371^{* *}$ & \\
& & $(0.0360)$ & \\
HML & & $-0.4074^{* *}$ & \\
& & $(0.0391)$ & \\
PR1 & & 0.0219 & \\
& & $(0.0329)$ & 0.0006 \\
CS & & & $(0.0009)$ \\
& & & \\
\hline $\mathbf{R}^{2}$ & 0.8690 & 0.9460 & \\
\hline
\end{tabular}




\section{Table 4}

\section{Annualized Returns for Time Decompositions of the Purchase and Sale Portfolios}

This table provides the annualized returns for decompositions of the purchase and sale portfolios into four holding periods: day0-day5, day5-day21, day21-month6, and month6year1. At the close of trading on the day of an insider transaction, the purchase or sale is placed into the day0-day5 portfolio; at the end of day 5, the trade is removed from the previous portfolio and placed into the day5-day 21 portfolio; etc. This decomposition is done separately for purchases and sales. The sample is from January 1, 1976 to December 31, 1996. The bottom row shows the annualized return on the value-weighted market for the same sample period.

\begin{tabular}{lcccc}
\hline & day0-day5 & day5-day21 & day21-month6 & month6-year1 \\
\hline Purchase & $57.6 \%$ & $34.7 \%$ & $23.2 \%$ & $18.3 \%$ \\
Sale & 28.9 & 18.9 & 15.3 & 16.6 \\
& & & & \\
\hline Market & $15.6 \%$ & $15.6 \%$ & $15.6 \%$ & $15.6 \%$ \\
\hline
\end{tabular}




\section{Table 5 \\ Performance-Evaluation Results for Time Decompositions of the Purchase and Sale Portfolios}

This table presents the performance-evaluation results for decompositions of the purchase and sale portfolios into four holding periods: day0-day5, day5-day21, day21-month6, and month6-year1. At the close of trading on the day that an insider transaction occurs, the purchase or sale is placed into the day0-day5 portfolio; at the end of day 5, the trade is removed from the previous portfolio and placed into the day5-day21 portfolio; etc. This decomposition is done separately for purchases and sales. The top of the chart shows the regression intercepts, $\alpha$, from the CAPM (equation 1). The middle shows the regression intercepts, $\alpha$, from the 4-factor model (equation 2). The bottom portion shows the CS measure (equation 3). Standard errors appear in parentheses. The symbols * and ** indicate two-tail significance at the five-percent level and one-percent level, respectively. The sample is from January 1, 1976 to December 31, 1996.

\begin{tabular}{|c|c|c|}
\hline & Purchase & Sale \\
\hline$\frac{\text { CAPM }}{\text { day0-day5 }}$ & $\begin{array}{l}0.0269 * * \\
(0.0032)\end{array}$ & $\begin{array}{l}0.0080 * * \\
(0.0023)\end{array}$ \\
\hline day5-day 21 & $\begin{array}{l}0.0129 * * \\
(0.0026)\end{array}$ & $\begin{array}{r}0.0015 \\
(0.0021)\end{array}$ \\
\hline day 21-month6 & $\begin{array}{l}0.0054 * * \\
(0.0020)\end{array}$ & $\begin{array}{r}-0.0016 \\
(0.0017)\end{array}$ \\
\hline month6-year1 & $\begin{array}{r}0.0019 \\
(0.0018)\end{array}$ & $\begin{array}{r}-0.0003 \\
(0.0017)\end{array}$ \\
\hline$\frac{\text { 4-Factor Model }}{\text { day0-day5 }}$ & $\begin{array}{l}0.0252 * * \\
(0.0032)\end{array}$ & $\begin{array}{l}0.0096 * * \\
(0.0022)\end{array}$ \\
\hline day5-day 21 & $\begin{array}{l}0.0114 * * \\
(0.0026)\end{array}$ & $\begin{array}{r}0.0010 \\
(0.0019)\end{array}$ \\
\hline day 21-month6 & $\begin{array}{r}0.0029 \\
(0.0016)\end{array}$ & $\begin{array}{r}-0.0010 \\
(0.0014)\end{array}$ \\
\hline month6-year1 & $\begin{array}{r}0.0008 \\
(0.0012)\end{array}$ & $\begin{array}{r}0.0007 \\
(0.0013)\end{array}$ \\
\hline$\frac{\text { CS Measure }}{\text { day0-day5 }}$ & $\begin{array}{l}0.0304 * * \\
(0.0031)\end{array}$ & $\begin{array}{l}0.0085^{* *} \\
(0.0020)\end{array}$ \\
\hline day5-day 21 & $\begin{array}{l}0.0136 * * \\
(0.0025)\end{array}$ & $\begin{array}{r}0.0031 \\
(0.0019)\end{array}$ \\
\hline day21-month6 & $\begin{array}{l}0.0036^{*} \\
(0.0018)\end{array}$ & $\begin{array}{l}-0.0001 \\
(0.0013)\end{array}$ \\
\hline month6-year1 & $\begin{array}{r}0.0019 \\
(0.0014)\end{array}$ & $\begin{array}{r}0.0016 \\
(0.0012)\end{array}$ \\
\hline
\end{tabular}




\section{Table 6}

\section{Performance-Evaluation Results for Trade-Volume Decompositions of the Purchase and Sale Portfolios}

This table presents the performance-evaluation results for decompositions of the purchase and sale portfolios by trade volume. To form our component portfolios, we first calculate the percentage of firm equity traded in each transaction. Next, we sort all trades by these equity percentages, with purchases and sales ranked separately. Based on these rankings, we divide purchases and sales into thirds: "low-volume", "medium-volume", and "high-volume". This yields cutoffs of 0.004 and 0.028 percent for the purchase thirds, and 0.010 and 0.048 percent for the sales thirds; i.e, all sales below 0.010 percent of firm equity are classified as low-volume, above 0.048 percent are classified as high-volume, and in-between as medium-volume. The top of the chart shows the regression intercepts, $\alpha$, from the CAPM (equation 1). The middle shows the regression intercepts, $\alpha$, from the 4-factor model (equation 2 ). The bottom portion shows the CS measure (equation 3). Standard errors appear in parentheses. The symbols * and $* *$ indicate two-tail significance at the five-percent level and one-percent level, respectively. The sample is from January 1, 1976 to December 31, 1996.

\begin{tabular}{|c|c|c|}
\hline & Purchase & Sale \\
\hline \multicolumn{3}{|l|}{ CAPM } \\
\hline$\overline{\text { low-volume }}$ & $\begin{array}{r}0.0010 \\
(0.0006)\end{array}$ & $\begin{array}{l}-0.0015^{* *} \\
(0.0007)\end{array}$ \\
\hline medium-volume & $\begin{array}{l}0.0049^{* *} \\
(0.0012)\end{array}$ & $\begin{array}{r}-0.0010 \\
(0.0012)\end{array}$ \\
\hline high-volume & $\begin{array}{l}0.0050^{* *} \\
(0.0019)\end{array}$ & $\begin{array}{r}0.0006 \\
(0.0017)\end{array}$ \\
\hline \multicolumn{3}{|l|}{ 4-Factor Model } \\
\hline low-volume & $\begin{array}{c}0.0013 * \\
(0.0006)\end{array}$ & $\begin{array}{r}0.0001 \\
(0.0007)\end{array}$ \\
\hline medium-volume & $\begin{array}{l}0.0039 * * \\
(0.0008)\end{array}$ & $\begin{array}{r}0.0003 \\
(0.0009)\end{array}$ \\
\hline high-volume & $\begin{array}{c}0.0040 * \\
(0.0014)\end{array}$ & $\begin{array}{r}0.0006 \\
(0.0011)\end{array}$ \\
\hline \multicolumn{3}{|l|}{ CS Measure } \\
\hline low-volume & $\begin{array}{l}0.0015^{* *} \\
(0.0005)\end{array}$ & $\begin{array}{r}0.0000 \\
(0.0006)\end{array}$ \\
\hline medium-volume & $\begin{array}{l}0.0046^{* *} \\
(0.0007)\end{array}$ & $\begin{array}{r}0.0003 \\
(0.0009)\end{array}$ \\
\hline high-volume & $\begin{array}{c}0.0043^{* *} \\
(0.0014)\end{array}$ & $\begin{array}{r}0.0008 \\
(0.0011)\end{array}$ \\
\hline
\end{tabular}




\section{Table 7}

\section{Performance-Evaluation Results for Trade-Volume Decompositions of the day0-day5 Purchase and Sale Portfolios}

This table presents the performance-evaluation results for decompositions of the day0-day5 purchase and sale portfolios by trade volume. The day0-day5 purchase (sale) portfolio includes all shares purchased (sold) by insiders over the previous five days. To decompose these portfolios by trade volume, we first calculate the percentage of firm equity traded in each transaction. Next, we sort all trades by these equity percentages, with purchases and sales ranked separately. Based on these rankings, we divide purchases and sales into thirds: "low-volume", "mediumvolume", and "high-volume". This yields cutoffs of 0.004 and 0.028 percent for the purchase thirds, and 0.010 and 0.048 percent for the sales thirds; i.e, all sales below 0.010 percent of firm equity are classified as low-volume, above 0.048 percent are classified as high-volume, and in-between as medium-volume. The top of the chart shows the regression intercepts, $\alpha$, from the CAPM (equation 1). The middle shows the regression intercepts, $\alpha$, from the 4-factor model (equation 2). The bottom portion shows the CS measure (equation 3). Standard errors appear in parentheses. The symbols * and ** indicate two-tail significance at the five-percent level and one-percent level, respectively. The sample is from January 1, 1976 to December 31, 1996.

\begin{tabular}{lcc}
\hline & Purchase & Sale \\
\hline CAPM & $0.0118^{* *}$ & $-0.0057^{* *}$ \\
low-volume & $(0.0019)$ & $(0.0018)$ \\
medium-volume & $0.0252^{* *}$ & -0.0048 \\
& $(0.0026)$ & $(0.0024)$ \\
high-volume & $0.0301 * *$ & $0.0131^{* *}$ \\
& $(0.0042)$ & $(0.0029)$ \\
4-Factor Model & & \\
low-volume & $0.0112^{* *}$ & $-0.0043^{*}$ \\
medium-volume & $(0.0021)$ & $(0.0019)$ \\
high-volume & $0.0240^{* *}$ & -0.0035 \\
& $(0.0025)$ & $(0.0023)$ \\
CS Measure & $0.0278^{* *}$ & $0.0144 * *$ \\
low-volume & $(0.0042)$ & $(0.0027)$ \\
& & \\
medium-volume & $0.0142^{* *}$ & $-0.0035^{*}$ \\
high-volume & $(0.0020)$ & $(0.0013)$ \\
& $0.0283^{* *}$ & -0.0021 \\
& $(0.0030)$ & $(0.0023)$ \\
& $0.0349 * *$ & $0.0130^{* *}$ \\
& $(0.0042)$ & $(0.0024)$ \\
& & \\
\hline
\end{tabular}




\section{Table 8}

\section{Performance-Evaluation Results for Firm-Size Decompositions of the Purchase and Sale Portfolios}

This table presents the performance-evaluation results for decompositions of the purchase and sale portfolios by firm size. At the beginning of each month, we divide the NYSE into thirds based on size (market value). We then use the cutoffs for these thirds to place all NYSE/AMEX/Nasdaq stocks into one of three categories: "small-firm", "medium-firm", and "large-firm". Each insider transaction is then placed into a portfolio on the day of the trade based on the size of the firm. This position stays in the same portfolio for the full year, even if the underlying firm crosses a size cutoff. This procedure results in six portfolios (three for purchases and three for sales). The top of the chart shows the regression intercepts, $\alpha$, from the CAPM (equation 1). The middle shows the regression intercepts, $\alpha$, from the 4 -factor model (equation 2). The bottom portion shows the CS measure (equation 3). Standard errors appear in parentheses. The symbols * and ** indicate two-tail significance at the five-percent level and one-percent level, respectively. The sample is from January 1, 1976 to December 31, 1996.

\begin{tabular}{lcr}
\hline & Purchase & Sale \\
\hline CAPM & $0.0051^{* *}$ & 0.0001 \\
small-firm & $(0.0019)$ & $(0.0021)$ \\
medium-firm & 0.0034 & -0.0008 \\
& $(0.0025)$ & $(0.0017)$ \\
large-firm & 0.0005 & -0.0009 \\
& $(0.0019)$ & $(0.0012)$ \\
4-Factor Model & & \\
small-firm & $0.0039 * *$ & 0.0008 \\
& $(0.0013)$ & $(0.0011)$ \\
medium-firm & 0.0021 & 0.0004 \\
large-firm & $(0.0022)$ & $(0.0013)$ \\
& 0.0015 & 0.0008 \\
CS Measure & $(0.0019)$ & $(0.0011)$ \\
small-firm & & \\
& $0.0031^{* *}$ & 0.0009 \\
medium-firm & $(0.0012)$ & $(0.0010)$ \\
large-firm & 0.0032 & -0.0003 \\
& $(0.0020)$ & $(0.0012)$ \\
\hline
\end{tabular}




\section{Table 9}

\section{Performance-Evaluation Results for Job-Title Decompositions of the Purchase and Sale Portfolios}

This table presents the performance-evaluation results for decompositions of the purchase and sale portfolios by job title of insider. "Top executives" are the subset of corporate officers that hold the title of chief executive, chairman of the board, or president. "Officers" include all corporate officers except for top executives. "Directors" are members of the corporate board who do not also hold an officer title. These categories do not overlap and cover all trades in our sample. This decomposition results in three purchase portfolios and three sale portfolios. The top of the chart shows the regression intercepts, $\alpha$, from the CAPM (equation 1). The middle shows the regression intercepts, $\alpha$, from the 4-factor model (equation 2). The bottom portion shows the CS measure (equation 3). Standard errors appear in parentheses. The symbols * and ** indicate two-tail significance at the five-percent level and one-percent level, respectively. The sample is from January 1, 1976 to December 31, 1996.

\begin{tabular}{lcc}
\hline & Purchase & Sale \\
\hline CAPM & 0.0040 & -0.0028 \\
top executive & $(0.0029)$ & $(0.0021)$ \\
officer & $0.0053^{*}$ & -0.0012 \\
& $(0.0021)$ & $(0.0014)$ \\
director & $0.0044^{* *}$ & -0.0003 \\
& $(0.0017)$ & $(0.0014)$ \\
4-Factor Model & & \\
top executive & 0.0028 & -0.0018 \\
& $(0.0028)$ & $(0.0019)$ \\
officer & $0.0054^{* *}$ & -0.0000 \\
director & $(0.0018)$ & $(0.0010)$ \\
& $0.0030^{*}$ & 0.0010 \\
CS Measure & $(0.0013)$ & $(0.0010)$ \\
top executive & & \\
director & 0.0010 & -0.0020 \\
& $(0.0028)$ & $(0.0017)$ \\
& $0.0046^{* *}$ & 0.0005 \\
& $(0.0017)$ & $(0.0010)$ \\
& $0.0040^{* *}$ & 0.0010 \\
& $(0.0013)$ & \\
\hline
\end{tabular}




\section{Table 10}

\section{Performance-Evaluation Results for Decompositions of the Purchase and Sale Portfolios between Direct and Indirect Trades}

This table presents the performance-evaluation results for decompositions of the purchase and sale portfolios between direct and indirect trades. Securities owned directly are those held in the reporting person's name. Securities owned indirectly are those held in the name of another person in which a reporting person has a pecuniary interest, by reason of any contract, understanding or relationship (including a family relationship or arrangement). The top of the chart shows the regression intercepts, $\alpha$, from the CAPM (equation 1). The middle shows the regression intercepts, $\alpha$, from the 4 -factor model (equation 2). The bottom portion shows the CS measure (equation 3). Standard errors appear in parentheses. The symbols $*$ and $* *$ indicate two-tail significance at the five-percent level and one-percent level, respectively. The sample is from January 1, 1976 to December 31, 1996.

\begin{tabular}{lcc}
\hline & Purchase & Sale \\
\hline CAPM & & \\
direct & $0.0060^{* *}$ & -0.0009 \\
& $(0.0016)$ & $(0.0014)$ \\
indirect & $0.0043^{*}$ & -0.0016 \\
& $(0.0019)$ & $(0.0016)$ \\
4-Factor Model & & \\
direct & $0.0051^{* *}$ & 0.0007 \\
& $(0.0012)$ & $(0.0010)$ \\
indirect & $0.0034 *$ & -0.0008 \\
& $(0.0016)$ & $(0.0013)$ \\
CS Measure & & \\
direct & $0.0060^{* *}$ & 0.0008 \\
& $(0.0011)$ & $(0.0010)$ \\
indirect & 0.0031 & -0.0002 \\
& $(0.0018)$ & $(0.0012)$ \\
\hline
\end{tabular}

